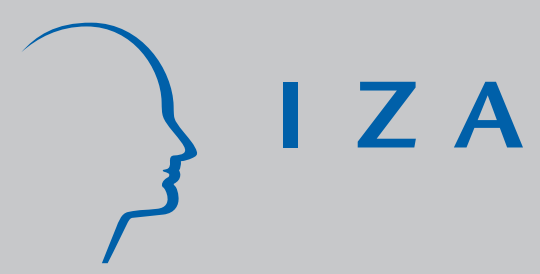

IZA DP No. 431

The Perception of Foreigners and J ews in Germany - A Structural Analysis of a Large Opinion Survey

Michael Fertig

Christoph M. Schmidt

February 2002 


\title{
The Perception of Foreigners and Jews in Germany - A Structural Analysis of a Large Opinion Survey
}

\author{
Michael Fertig \\ University of Heidelberg and IZA, Bonn \\ Christoph M. Schmidt \\ University of Heidelberg, CEPR and IZA, Bonn
}

Discussion Paper No. 431
February 2002

IZA

P.O. Box 7240

D-53072 Bonn

Germany

Tel.: +49-228-3894-0

Fax: +49-228-3894-210

Email: iza@iza.org

This Discussion Paper is issued within the framework of IZA's research area Evaluation of Labor Market Policies and Projects. Any opinions expressed here are those of the author(s) and not those of the institute. Research disseminated by IZA may include views on policy, but the institute itself takes no institutional policy positions.

The Institute for the Study of Labor (IZA) in Bonn is a local and virtual international research center and a place of communication between science, politics and business. IZA is an independent, nonprofit limited liability company (Gesellschaft mit beschränkter Haftung) supported by the Deutsche Post AG. The center is associated with the University of Bonn and offers a stimulating research environment through its research networks, research support, and visitors and doctoral programs. IZA engages in (i) original and internationally competitive research in all fields of labor economics, (ii) development of policy concepts, and (iii) dissemination of research results and concepts to the interested public. The current research program deals with (1) mobility and flexibility of labor, (2) internationalization of labor markets, (3) the welfare state and labor markets, (4) labor markets in transition countries, (5) the future of labor, (6) evaluation of labor market policies and projects and (7) general labor economics.

IZA Discussion Papers often represent preliminary work and are circulated to encourage discussion. Citation of such a paper should account for its provisional character. A revised version may be available on the IZA website (www.iza.org) or directly from the author. 
IZA Discussion Paper No. 431

February 2002

\section{ABSTRACT}

\section{The Perception of Foreigners and Jews in Germany - A Structural Analysis of a Large Opinion Survey*}

The ultimate aim of opinion surveys is the provision of information on the distribution of preferences and perceptions at the individual level. Yet, eliciting this information from the data is typically difficult. This paper uses a structural model to explain the answers on a set of questions regarding the perception of foreigners and Jews by native Germans. In this model it is assumed that in addition to observable individual characteristics there exists an underlying unobserved attitude towards minorities which drives the distribution of answers by native respondents. This latent variable in turn is assumed to be influenced by a set of observable socio-economic characteristics of the individuals. In order to estimate this model it is necessary to impose strong identification restrictions. Estimation results show that education is the key correlate of the perception of foreigners and Jews in Germany.

JEL Classification: $\quad$ C31, F22, J15

Keywords: Attitudes, minorities, identification

Christoph M. Schmidt

Department of Economics (Econometrics)

University of Heidelberg

Grabengasse 14

69177 Heidelberg

Germany

Tel.: +49-6221-54 2955

Fax: +496221543640

Email: schmidt@uni-hd.de

*The authors are grateful to Timothy Guinanne, Christian Dustmann and participants of the CEPR/EUIconference on Labour Demand, Education and the Dynamics of Social Exclusion, Florence, 2001 for helpful comments and Markus Tamm for research assistance. 


\section{Introduction}

To any student of German history it does not come as a surprise that the possible existence of xenophobic or antisemitic tendencies in the German society is a continuing topic of the public debate and a frequent subject of empirical analysis. Indeed, numerous articles in well-respected periodicals are regularly concerned with this issue. Typically, the statistical investigation documents considerable heterogeneity in attitudinal responses throughout the population. Most of these articles then relate these tendencies monocausally to a specific observable factor, like education or age, and provide detailed structural explanations for this suspected relationship despite the obvious conceptual limitations of such an approach.

A case in point is the debate regularly set off by an opinion survey conducted among young people in Germany on behalf of the company Shell (the so-called Shell-Jugendstudie, cf. Fischer ET AL. (2000)). In this study, the opinions expressed by young respondents are presented on a semi-aggregated level, differentiated one by one by sex, age groups, personal future expectations and other characteristics. Unfortunately, this presentation does not provide an attempt at explaining the observed patterns more deeply, although structural explanations are suggested: most importantly, the authors not only claim that serious xenophobic attitudes among young people in Germany persist, but even more speculatively that these attitudes are mainly the result of the dull economic prospects of the respondents. They propose, therefore, that an adequate counter-strategy must be a program aiming at the enhancement of the education and formal training possibilities of German youth.

Drawing such strong conclusions on the basis of such cursory evidence, however, must be problematic. The conceptual problems facing the empirical analysis of xenophobic tendencies are indeed substantial. The first problem arises from the definitional question of what has to be understood as a xenophobic or antisemitic attitude, and to what degree such attitudes are measurable. Since both concepts reflect fundamental issues of individual opinion neither is directly measurable. On a superficial level, one may define xenophobia and antisemitism as especially negative individual attitudes towards foreigners and Jews, respectively. Yet, it is not a question of relatively (compared to the population average) xenophobia which is typically at issue, but rather a statement about an absolute level of racism or xenophobia which is sought.

Since racist ideas are typically emotional, subjective, and frequently distorted interpretation of observable facts, a possible conceptualization of xenophobia and antisemitism could depart from a notion of mistaken perceptions. Such attitudes have certainly almost always nothing to do with the "true" characteristics of the relevant groups. They are rather the result of subjective perceptions of an individual which is projecting real or imaginary characteristics of some individuals onto a complete group of individuals. Therefore, a broad definition of xenophobia and antisemitism would qualify every individual which is willing to generalize negative individual-specific characteristics to a group of individuals to which he/she does not belong himself/herself as xenophobic or antisemitic.

In addition to providing such a general definition, we can characterize these concepts further. Specifically, both concepts are by their very nature relative, i.e. there is no 
scale to measure them absolutely (all attempts to do so in the literature are completely arbitrary). For instance, an individual may have a significantly more negative attitude towards a minority group than the average individual in a given society and may therefore be termed (relatively) xenophobic or antisemitic. However, the same individual living in an, on average, foreigner-friendly society will be easier regarded as xenophobic than the same individual being citizen of an, on average, less foreigner-friendly society.

Finally, a priori it is not clear if xenophobia and antisemitism are different concepts or if they are intimately related. AdORNO ET AL. (1950), for instance, argue that antisemitism is not an isolated phenomenon but rather part of a much broader ideological system. Nevertheless, this paper examines opinions towards foreigners and Jews separately in order to investigate if the determining factors of attitudes towards both minority groups are driven by different explanatory factors. This analysis will provide us with some indications that the determining factors of both are at least in part different.

For the purposes of scientific analysis of underlying preferences and perceptions, any opinion survey without detailed background information on the respondents themselves would be quite useless. Fortunately, in Germany there exists a dataset regularly collected by the GESIS (Gesellschaft sozialwissenschaftlicher Struktureinrichtungen), the so-called ALLBUS (Allgemeine Bevölkerungsumfrage der Sozialwissenschaften), which is comparable to the General Social Survey in the United States. This opinion and attitude survey is publicly available and conducted biennially with varying focuses on different topics (for more details see section 4). The 1996 wave contains a large set of questions ${ }^{1}$ on the perception of immigrants, foreigners and other minorities as well as standard socio-economic characteristics. Several empirical studies investigate this 1996 wave information, albeit not in the direction taken by this contribution (for more details see section 2). In our own empirical application we utilize this dataset as well. Specifically, we aim at the identification and explanation of unobservable underlying factors driving those opinions towards minorities which are expressed by native respondents in the survey.

Conceptually, this paper contributes to the received literature by using a structural model to explain the answers on a set of questions regarding the perception of minorities by native Germans. In this model it is assumed that in addition to observable individual characteristics, there exists an underlying unobserved attitude towards minorities which drives the distribution of answers by native respondents. This latent variable in turn is assumed to be shaped by a set of observable socio-economic characteristics of the individuals. It is the direction and magnitude of these effects on the unobservable factor which are the primary objects of our interest. In order to estimate this model it is necessary to impose appropriate identification restrictions. The restrictions employed in our empirical application are discussed in detail below. The validity of these assumptions is decisive for the interpretation of the results. However, since these restrictions are non-testable they have to be assumed to hold a priori. Naturally, without such identification assumptions a well-structured analysis of the wealth of information provided by opinion surveys like the $A L L B U S$ is impossible.

\footnotetext{
${ }^{1}$ Precisely, the ALLBUS records items in the form of direct standardized questions to which respondents are supposed to give an answer and in the form of claims for which respondents should state their degree of agreement/disagreement. For the sake of exposition we will unequivocally call them items or questions in what follows.
} 
The paper is organized as follows. The next section provides a brief survey of the received literature on the perception of foreigners. In section 3 the utilized structural model, its reduced-form counterpart as well as the employed identification strategy are explained. Section 4 contains our empirical application for Germany and, finally, section 5 offers some conclusions.

\section{Attitudes - Survey of Literature}

The literature in sociology and (social-) psychology as well as historical research (e.g. BENZ (1992 ff)) is the primary source of theoretical work on the determinants of xenophobic or antisemitic attitudes. Prominent (but mainly) theoretical approaches are the authoritarian (e.g. Adorno ET AL. (1950)), the ethnocentristic (e.g. Sumner (1906)) and the rational choice (e.g. FishBEIN AND AiJzEN (1975)) approach. Empirical evidence for these approaches is rather slim, though. Most of the empirical studies present purely descriptive results, making it difficult to disentangle the various structural interpretations.

One early and rather prominent study on attitudes towards minorities is ADORNO ET AL. (1950) conducted in the United States in the 1940's. This study aims at investigating the potential for anti-democratic or fascist influences in the US-american society during and directly after World War II and is motivated by the idea that individual attitudes are manifestations of the individual character structure. This character structure is assumed to be formed by influences emanating from the individual's environment. This environment has the most thorough impact the earlier in life the influence works. This means that the education of a child and his or her parental, economic as well as social, background is the most influential tool in building the character structure which in turn serves as the foundation of individual attitudes. ADORNO ET AL. (1950) conducted more than 2,000 interviews and some clinical trials to provide support for their main hypotheses. One of the most interesting features of this study is the so-called F(ascism)-scale. This scale aims at measuring the individual fascist potential indirectly, i.e. by a set of questions addressing a variety of individual opinions which are not directly related to political attitudes towards democracy or fascism. The study tried to establish the individual fascist potential by investigating the individual degree of conventionalism, authoritarian aggression, superstition, cynicism etc. as indications for fascist tendencies.

For the case of United Kingdom Dustmann And Preston (2000A), using several waves of the British Social Attitude Survey, (BSAS) analyze the effect of local concentration of ethnic minority groups on the attitudes of native respondents towards these minorities controlling for individual characteristics of the respondents as well as for regional labor market conditions. Their results suggest that a higher concentration of ethnic minorities tends to increase hostitility of native respondents towards these groups. Dustmann And Preston (2000B), again using the BSAS data, analyze the relationship between racist attitudes, as well as labor market and welfare considerations with the opinions of native respondents towards future immigration (restrictions) for different immigrant groups. Thereby, they base their formal analysis on a multi-factor model. One 
key feature of their paper is the provision of a formal treatment of identification issues in such a framework.

Most importantly, the authors aim at explaining the determining factors of individuals' opinions towards future immigration (restrictions) for different potential immigrant groups. For this purpose they utilize a set of questions on the perception of foreigners by native respondents in the $B S A S$, regarding different aspects. They devide these questions into three categories: (i) questions related to race, (ii) questions related to the labor market impact of foreigners, and (iii) questions related to the impact of foreigners on the economy's welfare. In order to disentangle the influence of these three categories on the opinion of respondents, Dustmann AND PRESTON (2000B) invoke the identification assumptions that each of the three latent factors manifests itself in a set of four corresponding questions, respectively. The three factors, thus identified, then explain jointly the answers on a large set of attitudinal questions on future immigration. In this second step, the three factors compete for the leading explanatory role regarding these opinions.

Their results suggest that opposition to future immigration is primarily driven by racist attitudes whereas labor market or welfare considerations are less important determining factors. This relationship is particularly strong for future immigration of ethnically different immigrant groups, such as people from the West-Indies, whereas it is negligible for ethnically similar groups, such as from Australia or New Zealand. In sum, while the chosen identification strategy is powerful enough to extract sensible results on the effect of the latent factors, this strategy is necessarily restrictive. The present contribution takes a somewhat different perspective, since we concentrate on a single latent factor only, but are mainly interested in the question which forces underlie its formation rather than merely gauging its impact.

A contribution for the case of Germany is GANG AND RiverA-BATIZ (1994). Using the Eurobarometer survey of 1988, the authors, among others, aim at examining the attitudes towards foreigners in Germany in relation to different labor market situations of native respondents. They conclude that students have the most positive attitude towards foreigners and retirees the most negative. Concerning employment status, negative attitudes by unemployed Germans are more prevalent if the analyzed questions explicitly address specific foreigner groups. BAUER, LofSTrom AND ZimmERMANN (2000) using the 1995 wave of the International Social Survey Program (ISSP) provide a cross country comparison with a special focus on the influence of immigration policy on attitudes towards minorities. Their main conclusion is that in countries with a more skill-based immigration policy (e.g. Canada) respondents tend to have a more positive attitude towards immigrants and other minorities than countries which pursue another immigration policy.

Finally, Fertig And SCHMidT (2001) using the 1996 wave of the ALLBUS provide an analysis of the perception of the welfare dependence of immigrants by native Germans in an ordered probit framework and confront this perception with the actual welfare dependence of immigrants using the 1995 wave of the Mikrozensus. They conclude that the level of education of the respondents as well as their place of residence are the main driving forces behind the distribution of agreement with the (not really compatible with observable facts) claim that foreigners are a burden for the social security system in Ger- 
many. Furthermore, respondents living in regions with a below-average share of foreigners have a considerably higher probability to agree with this claim, whereas living in a region with a high share of foreigners has no statistically significant impact.

For the 1996 wave of the ALLBUS several empirical studies are collected in ALBA ET AL. (2000). Examples are BERGMAnn AND ERB (2000), LüDEMAnn (2000) and SCHMIDT AND HEYDER (2000). These papers analyze the attitudes of German respondents towards minorities in the ALLBUS 1996 embedded in the theoretical concepts of authoritarism, ethnocentrism and rational choice. They all share the empirical strategy of explaining some selected items recorded in the ALLBUS by using other opinions towards foreigners or Jews as explanatory factors, without taking into account the potential endogeneity or simultaneity arising from such an approach. Moreover, some of these studies also construct indices of antisemitism or xenophobia without taking into account the ordinal nature of the opinion scale. Similarly, some of these studies try to classify respondents as xenophobic or antisemitic by rather arbitrary classification rules, e.g. two or more negative answers to a given set of questions regarding Jews qualifies an individual as having an antisemitic attitude. In our own approach, described in detail in the next section, we explicitly aim at avoiding such conceptually problematic ad hoc decisions.

\section{The Framework of Analysis}

In our analysis on the attitudes towards minorities in Germany we aim at utilizing the wealth of information on attitudes expressed in the ALLBUS 1996 wave to generate a comprehensive picture of the perception of immigrants and foreigners in Germany. For this purpose, we develop a structural simultaneous equation model to explain the distribution of answers to each relevant item. The 1996 wave of the ALLBUS contains several items on the perception of different minority groups in Germany. From this menu we choose 35 questions concerning immigrants/foreigners and seven questions concerning Jews (see Appendix for a description of the relevant questions) covering a variety of aspects of daily life as well as fundamental issues of opinion. Only those items were left out of the analysis where a clear distinction between a positive and a negative attitude was not possible. Although all questions offered the possibility to withhold the answer, the response rate to all of them was very high, yielding a sample of 2,834 native respondents $(1,844$ in West and 990 in East Germany). From the 3,290 native individuals in the dataset, we deleted all observations with an incomplete record of all 42 utilized questions.

Central to our approach is the maintained assumption of the presence of an underlying, unobservable or latent, overall opinion towards minorities, which drives the distribution of answers by respondents and which we would like to extract from the observable data. Respondents' answers are, therefore, regarded as the manifestation of this latent opinion and this manifestation may vary from question to question since the degree with which a respondent's opinion is sifted out by a specific question may vary from one question to another. Moreover, we allow for a separate impact of exogenous socio-economic factors explaining the distribution of answers to each question beyond the influence of the overall factor. These socio-economic characteristics also comprise the determining factors of the underlying overall opinion. Their influence on the latent factor is the central object of 
our interest.

As already pointed out in the introduction, it is tempting to regard this underlying latent variable as xenophobia or antisemitism. However, this may be misleading due to two reasons. Firstly, it is an assumption that there exists only one latent variable driving the opinions of respondents. From a psychological point of view one may e.g. argue that there exist two (or even more) factors having an influence on respondents' perception of foreigners. Since the labelling of latent factor can proceed without any restriction whatsoever, one could call these two factors "xenophobia" and "misanthropy", for instance. Therefore, restricting the analysis to only one factor does not render the results invalid as long as the underlying factors all operate in the same direction, but it renders the name of the latent variable inappropriate. Secondly, comparable to the classical approaches like principal component, latent factor or latent class analysis, giving names to unobservable factors is a rather arbitrary endeavor. Our analysis as well as competing alternatives only allow to assess whether an assumed latent variable does have an influence on observed opinions. It does not, however, reveal the nature or the name of this influence.

Formally, in our application we model the opinions expressed by native respondents in the $A L L B U S$ in a simultaneous equations framework containing one unobservable latent factor and several observables as explanatory variables. The next section, therefore, formalizes our structural model and derives its reduced-form counterpart. Then, we derive our identification strategy to disentangle the different determining factors of the latent attitude.

\subsection{The Structural Model}

Our dataset contains $i=1, \ldots, N$ individuals (henceforth individual subscripts are suppressed for the purpose of exposition) for which we observe a set of $J$ answers $x_{j}(j=$ $1, \ldots, J)$ to questions on minorities in Germany. For all of them, there are three ordered answer categories, that is for each $i$ we have $x_{j} \in\{0,1,2\}$. Moreover, for each individual we observe $K$ socio-economic characteristics $Z_{k}(k=1, \ldots, K)$. Unobservable are for each individual $i$ the latent variables $x_{j}^{*}$ and $Y^{*}$. The variable $x_{j}^{*}$ may take values on the entire real line and denotes the "true", but unobservable opinion on question $j$ with large values representing strong agreement for each individual. The variable $Y^{*}$ denotes the unobservable overall opinion towards minorities which is assumed to be driving the distribution of answers to each question for each individual.

These two latent variables differ in the fact that we have an observable counterpart $x_{j}$ for $x_{j}^{*}$ but no comparable variable for $Y^{*}$. This variable might only be revealed through the answers (that is through the $x_{j}$ as well) in connection with a specific structural model. Finding this model is the key element of the discussion offered here. Therefore, we have the structural form 


$$
\begin{aligned}
x_{1}^{*} & =\delta_{0}^{1}+\delta_{1}^{1} Y^{*}+\beta_{1}^{1} z_{1}+\beta_{2}^{1} z_{2}+\ldots+\beta_{K}^{1} z_{K}+\epsilon^{1} \\
x_{2}^{*} & =\delta_{0}^{2}+\delta_{1}^{2} Y^{*}+\beta_{1}^{2} z_{1}+\beta_{2}^{2} z_{2}+\ldots+\beta_{K}^{2} z_{K}+\epsilon^{2} \\
& \vdots \\
x_{J}^{*} & =\delta_{0}^{J}+\delta_{1}^{J} Y^{*}+\beta_{1}^{J} z_{1}+\beta_{2}^{J} z_{2}+\ldots+\beta_{K}^{J} z_{K}+\epsilon^{J},
\end{aligned}
$$

where the mean-zero random disturbances $\epsilon^{j} \sim N\left(0, \sigma_{j}^{2}\right)(j=1, \ldots, J)$. The correlation structure between questions is block-diagonal across individuals, but left unspecified for any individual. For the latent variable $Y^{*}$, we assume that it can be explained partially by a set of observable socio-economic characteristics $Z_{k}(k=1, \ldots, K)$. For each individual there is, in addition, a mean-zero random disturbance $\eta$ in this equation, such that $\epsilon$ and $\eta$ are orthogonal, i.e. $\operatorname{Cov}\left(\epsilon^{j}, \eta\right)=0(\forall j=1, \ldots, J)$. Therefore,

$$
Y^{*}=\gamma_{1} z_{1}+\gamma_{2} z_{2}+\ldots+\gamma_{K} z_{K}+\eta
$$

Both equations are written in deviations form, i.e. $z_{k}:=Z_{k}-\bar{Z}_{k} \forall k=1, \ldots, K$. Thus, if we would observe all latent variables directly, then $Y^{*}$ would be defined in a way that emphasized deviations from the typical individual in the population. Respondents with average characteristics $Z_{k}=\bar{Z}_{k}$ will, on average, display a latent factor $Y^{*}$ equal to zero, with deviations driven exclusively by the random factor $\eta$. If an observable characteristic $Z_{k}$ tends to increase the latent factor $Y^{*}$, that is $\gamma_{k}>0$, then individuals displaying a high $Z_{k}$ will also display a high $Y^{*}$. Perfect collinearity between $Y^{*}$ and the $Z_{k}(k=1, \ldots, K)$ is ruled out by the presence of the disturbance term $\eta$, though. In expression (1), the average "true" opinion $x_{j}^{*}$ for a typical individual $\left(Z_{K}=\bar{Z}_{k}\right)$ is reflected by the respective constant term $\delta_{0}^{j}$, as $E(\eta)=E\left(\epsilon^{j}\right)=0$. For all individuals the "true" opinion $x_{j}^{*}$ is influenced by their $Z_{k}$, but also by $Y^{*}$. The impact of $Y^{*}$ is captured by a coefficient $\delta_{1}^{j}$ which may be positive or negative.

Clearly, since there is no observable counterpart for the latent variable $Y^{*}$, direct estimation of the structural model is impossible. However, it is possible to derive an estimable reduced-form model and to identify the parameters of the structural model by invoking suitable assumptions. These identification assumptions are discussed in the next section.

\subsection{The Reduced Form}

By substituting equation (2) into equation (1) one obtains the reduced-form equation system

$$
\begin{aligned}
x_{1}^{*} & =\theta_{0}^{1}+\theta_{1}^{1} z_{1}+\theta_{2}^{1} z_{2}+\ldots+\theta_{K}^{1} z_{K}+\nu_{1} \\
x_{2}^{*} & =\theta_{0}^{2}+\theta_{1}^{2} z_{1}+\theta_{2}^{2} z_{2}+\ldots+\theta_{K}^{2} z_{K}+\nu_{2} \\
& \vdots \\
x_{J}^{*} & =\theta_{0}^{J}+\theta_{1}^{J} z_{1}+\theta_{2}^{J} z_{2}+\ldots+\theta_{K}^{J} z_{K}+\nu_{J},
\end{aligned}
$$


where

$$
\begin{gathered}
\theta_{0}=\left(\begin{array}{c}
\delta_{0}^{1} \\
\delta_{0}^{2} \\
\vdots \\
\delta_{0}^{J}
\end{array}\right) ; \theta_{1}=\left(\begin{array}{c}
\delta_{1}^{1} \gamma_{1}+\beta_{1}^{1} \\
\delta_{1}^{2} \gamma_{1}+\beta_{1}^{2} \\
\vdots \\
\delta_{1}^{J} \gamma_{1}+\beta_{1}^{J}
\end{array}\right) ; \theta_{2}=\left(\begin{array}{c}
\delta_{1}^{1} \gamma_{2}+\beta_{2}^{1} \\
\delta_{1}^{2} \gamma_{2}+\beta_{2}^{2} \\
\vdots \\
\delta_{1}^{J} \gamma_{2}+\beta_{2}^{J}
\end{array}\right) ; \ldots ; \\
\theta_{K}=\left(\begin{array}{c}
\delta_{1}^{1} \gamma_{K}+\beta_{K}^{1} \\
\delta_{1}^{2} \gamma_{K}+\beta_{K}^{2} \\
\vdots \\
\delta_{1}^{J} \gamma_{K}+\beta_{K}^{J}
\end{array}\right) ; \nu=\left(\begin{array}{c}
\delta_{1}^{1} \eta+\epsilon^{1} \\
\delta_{1}^{2} \eta+\epsilon^{2} \\
\vdots \\
\delta_{1}^{J} \eta+\epsilon^{J}
\end{array}\right) .
\end{gathered}
$$

This reduced-form equation system can be estimated by applying independent ordered probits to all $J$ equations separately. This yields consistent, though inefficient estimates $\hat{\theta}_{k}$ for $\theta_{k}(k=1, . ., K)$, since the information on the dependence of these equations contained in the error term $\nu$ is ignored by such a procedure.

Ordered probit analysis is a single-equation technique which assumes that there is an unobservable latent variable $x^{*}$ which linearly depends on a set of exogenous variables denoted by $z$ and an unobservable error term $\nu$. One does not observe $x^{*}$ directly but $x$, where $x$ is defined as

$$
\begin{gathered}
x=0 \text { if } \\
x=1 \text { if } \quad 0 \quad x^{*} \leq 0, \\
x=2 \text { if } \mu_{1} \leq x^{*} \leq \mu_{1}, \\
\vdots \\
x=L \text { if } \mu_{L-1} \leq \mu_{2}, \\
x x^{*} .
\end{gathered}
$$

The $\mu$ 's are unknown parameters to be estimated and can be regarded as threshold values. The idea behind this model formulation is that there exists a certain intensity of opinion which is an unobservable latent variable for the analyst, but can be explained by a set of measurable factors and an unobservable error term. The only difference to the modelling idea behind (1) is that the latent factor $Y^{*}$ has been purged from the right-hand side.

Moreover, it is assumed that this unobservable intensity of opinion is reflected by the observable categories, i.e. whenever a certain threshold value $\mu_{j}$ is exceeded one observes an individual in category $j+1$. This means that respondents choose the category which represents most closely their true opinion on the question. In the example at hand, we have three categories, i.e. $L=2$. We have coded all variables such that zero denotes a positive attitude, two denotes a negative attitude and one is the medium category. Finally, we assume that the error term is normally distributed, i.e. $\nu \sim N(0,1)$ and all elements of $\nu$ are uncorrelated across respondents. This implies that $\eta$ and $\epsilon$ are normally distributed as well, since $\epsilon$ was assumed to be normally distributed. 


\subsection{Identification of Structural Parameters}

The parameters of interest are the $\gamma_{k}(k=1, \ldots, K)$, determining the impact of measurable socio-economic characteristics on the unobserved overall attitude towards minorities. However, these parameters are not identifiable from the estimated reduced form parameters without further restrictions. Unfortunately, the (Cowles-Commission-type) classical literature on simultaneous equation systems does not offer much guidance since exclusion restrictions are very arbitrary in the case at hand.

Naturally, all identification strategies depend on a set different assumptions which have to be assumed to hold a priori. Unfortunately, no possibility exists to discriminate empirically between the appropriateness of these different assumptions. They have to be judged upon economic reasoning alone. Thus, we have to concentrate on what we want to achieve. Our ultimate aim is to identify the impact of the measurable socio-economic characteristics on the unobserved component $Y^{*}$ which itself drives the perception of foreigners and Jews by native Germans. Intuitively, the idea of our identification strategy in this particular case adheres to the following considerations.

In the structural model we assumed that there are two categories of explanatory factors at work to explain the distribution of answers on the questions in the ALLBUS. The first variable, the unobservable component $Y^{*}$, exhibits a direct influence via the parameter $\delta_{1}^{j}(j=1, \ldots, J)$. The observable socio-economic variables $Z_{k}(k=1, \ldots, K)$, however, impinge upon the answers directly and indirectly. Their direct influence is captured by the parameters $\beta_{k}^{j}$ whereas the indirect impact works through the parameters $\gamma_{k}$. In order to identify the latter parameters we assume that the direct impact of a specific socio-economic variable over all questions is on average zero.

This assumption retains the idea that the direct impact of a specific $Z_{k}$ on respondents' answers varies from question to question, just as in the original model (1). Yet, to the extent that this influence of $Z_{k}$ is the same on all questions, this influence is fully captured by the latent factor $Y^{*}$. In other words, the variable $Z_{k}$ can not influence the tendency on all questions in the same fashion in any other way than by shifting $Y^{*}$.

Formally, we assume that

$$
\frac{1}{J} \sum_{j=1}^{J} \beta_{k}^{j}=0 \quad \forall k=1, . ., K
$$

which yields

$$
\bar{\theta}_{k}=\frac{1}{J} \sum_{j=1}^{J} \theta_{k}^{j}=\frac{1}{J} \gamma_{k} \sum_{j=1}^{J} \delta_{1}^{j} \forall k=1, . ., K .
$$

Furthermore, we need a way to disentangle the influence of $Z_{k}$ on $x_{j}^{*}$ via $Y^{*}$ (that is, $\gamma_{k}$ ) from the influence of $Y^{*}$ itself on the $x_{j}$ (that is, the $\delta_{1}^{j}$ ). Clearly, the same set of $\theta_{k}^{j}$ 's can result from high $\gamma_{k}$ 's corresponding with low $\delta_{1}^{j}$ 's and vice versa. If the $x_{j}^{*}$ were metric

variables, and thus the $\theta_{k}^{j}$ were directly interpretable we would be hesitant to impose any normalization. Here, however, we can proceed directly and assume that the direct impact of the unobserved component measured by $\delta_{1}^{j}$ over all questions averages one. Formally, 
we assume that

$$
\frac{1}{J} \sum_{j=1}^{J} \delta_{1}^{j}=1
$$

That is, if the latent factor is important for the answers, that is, for $x_{j}^{*}$, then this will be reflected in $\gamma_{k}$ 's which are large. In consequence, we finally have

$$
\gamma_{k}=\bar{\theta}_{k} \quad \forall k=1, . ., K
$$

Due to the latent nature of $x_{j}^{*}$, and to our normalization in $(7)$, we can interpret the estimated $\gamma_{k}$ only in relative terms, that is compare the impact of $Z_{k}$ on $Y^{*}$ relative to that of $Z_{l}$ on $Y^{*}$. That is, since the level impact of $Z_{k}$ operates exclusively through $Y^{*}$, the average reduced-form impact of $Z_{k}$ captures its influence on $Y^{*}$ via $\gamma_{k}$. More important $Z_{k}$ will exert their influence through higher coefficients $\gamma_{k}$, on average.

This setup allows those structural equations with low variances in the disturbances to exert a more substantial influence on the estimate of $\gamma_{k}$. High disturbances in the structural-form equations lead to high variances in the corresponding reduced-form equations, i.e. to high $\sigma_{\nu_{j}}^{2}$. The normalization inherent in ordered probit analysis in turn leads to small reduced-form parameter estimates. Therefore, the estimated reduced-form coefficients of equations with low explanatory power receive a low weight in the calculation of the structural parameters $\gamma_{k}$.

Since these structural parameters are linear functions of the estimated reduced form parameters, their standard errors can be constructed straightforwardly from the covariances of the different reduced-form estimators. However, since we perform the estimation of these reduced-form parameters independently, we need a strategy to assess the cross-equation correlations of the parameter estimates. This is done by bootstrapping the variances and covariances of the different reduced-form coefficients over all questions. We then estimated the standard error of $\gamma_{k}$ as the positive square root of the estimated variance of $\gamma_{k}$. Specifically, from equations (6) and (8) we have for each $k=1, \ldots, K$

$$
\widehat{\operatorname{Var}}\left(\hat{\gamma}_{k}\right)=\widehat{\operatorname{Var}}\left(\hat{\bar{\theta}}_{k}\right)
$$

where

$$
\widehat{\operatorname{Var}}\left(\hat{\bar{\theta}}_{k}\right)=\widehat{\operatorname{Var}}\left(\frac{1}{J} \sum_{j=1}^{J} \hat{\theta}_{k}^{j}\right)=\frac{1}{J^{2}} \widehat{\operatorname{Var}}\left(\sum_{j=1}^{J} \hat{\theta}_{k}^{j}\right)
$$

and

$$
\widehat{\operatorname{Var}}\left(\sum_{j=1}^{J} \hat{\theta}_{k}^{j}\right)=\sum_{j=1}^{J} \widehat{\operatorname{Var}}\left(\hat{\theta}_{k}^{j}\right)+2 \cdot\left[\sum_{j=1}^{J} \sum_{l=1}^{J-1} \widehat{\operatorname{Cov}}\left(\hat{\theta}_{k}^{j}, \hat{\theta}_{k}^{l}\right)\right] .
$$

Collecting terms yields for the variance of the structural parameter $\gamma_{k}$

$$
\widehat{\operatorname{Var}}\left(\hat{\gamma}_{k}\right)=\frac{1}{J^{2}}\left\{\sum_{j=1}^{J} \widehat{\operatorname{Var}}\left(\hat{\theta}_{k}^{j}\right)+2 \cdot\left[\sum_{j=1}^{J} \sum_{l=1}^{J-1} \widehat{\operatorname{Cov}}\left(\hat{\theta}_{k}^{j}, \hat{\theta_{k}^{l}}\right)\right]\right\} .
$$

Thus, the estimated variance of the structural parameter $\gamma_{k}$ identified by our strategy is a linear function of the estimated variances of all reduced form parameters $\gamma_{k}^{j}$ and the estimated cross-equation covariances. 


\section{Empirical Evidence}

In this section we employ our approach to data available in the 1996 wave of the $A L L$ $B U S$. The $A L L B U S$ is a publicly available, biennially conducted opinion and attitude survey with varying focuses on different topics. The sample is drawn out of all individuals living in private households who, for the 1996 wave, have been born prior to January, 1st 1978. This wave, conducted between March and June 1996, contains questions on the perception of and attitudes towards immigrants, foreigners and Jews as well as standard socio-economic characteristics of the respondents. The majority of the respondents are native Germans but there is also a representative share of foreigners in the sample. Overall, native respondents perceive foreigners and Jews with a considerable degree of skepticism (for more details on the perception of foreigners see FERTIG AND SCHMIDT (2001)). Unfortunately, most of the items recorded in the ALLBUS do not differentiate between different minority groups. Only some of the questions explicitly address attitudes towards specific immigrant groups, like Turks, Italians, ethnic Germans, and asylum seekers. However, there is a set of questions which explicitly addresses the perception of Jews (for a description of these items cf. Appendix Table A.1 and Table A.2).

Originally, for most of the items utilized in this paper there were seven categories of possible agreement/disagreement with the claims expressed on an ordered scale reaching from (1) "I do not agree at all" to (7) "I agree completely". These seven possibilities were condensed into three categories: (1) and (2) into "no agreement", (6) and (7) into "agreement" and the other three original categories into "medium" (this scale is denoted by CoDing A). Only a small number of questions were originally coded on a three answer possibilities scale (see Table A1). For these questions we preserved the original scale. Furthermore, we checked the sensitivity of the results regarding the coding of the dependent variable by introducing a second scale denoted by CoDING B. In this alternative we combined all agreement categories, i.e. (5), (6) and (7), into "agreement" and all disagreement categories, i.e. (1), (2) and (3), into "no agreement". Therefore, only the original category (4) is now "medium". These answer categories are the dependent variables in our estimation approach.

\subsection{Background - Germany in 1996}

It seems natural to suppose that answers to opinion surveys can not be regarded as independent from the overall situation in which the questions are asked. Political actions and campaigns, opinions expressed in the media or other developments within society probably have an influence on respondents answers. Unfortunately, large opinion surveys like the $A L L B U S$ are not conducted with an identical setup several years in a row. However, we think it is illustrative for the interpretation of the results to have at least some knowledge on the historical background before which the questions were asked. Therefore, we will briefly sketch the situation in Germany in 1996 with a focus on the developments regarding minorities.

In 1996 the total population in Germany amounted to around 82 million people, of which approximately 7.5 million were non-citizens and around 70,000 were Jews. The biggest non-citizen groups were Turks with approximately 2 million members, followed by 
roughly 1.2 million people from former Yugoslavia and around 600,000 Italians (FEDERAL Statistical Office (1997)). On the federal level Germany had been governed by a parliamentary coalition of the Christian Democratic Union $(C D U)$, the Christian Social Union $(C S U)$, and the Free Democratic Party (FDP) since 1982.

In the course of the year, political debates arose around high social welfare cost, the restriction of worker rights (especially sickness payments), excessive tax rates and the adequate fiscal policy to meet the Maastricht criteria for access to the European Monetary Union. The real GDP growth rate declined to 1.4 per cent compared to 1.8 per cent in 1995 and the unemployment rate climbed to around 11 per cent on the federal level. Unemployment figures for the eastern part of Germany were much higher, though. In 1996 the mark of 4 million people registered as unemployed had been exceeded for the first time since 1929 .

The right to apply for asylum guaranteed by the German constitution (Grundgesetz) had been tightened in 1993 and applications had decreased dramatically since then. In 1996 there were 116,367 applications compared to 127,937 in 1995 and even 438,191 in the peak year 1992. The biggest group of applicants in that year came from former Yugoslavia, followed by Turkey. The number of ethnic Germans from eastern Europe (Aussiedler) decreased as well, to 177,751 people compared to 217,898 in 1995 and around 400,000 in the peak year 1990 .

During 1996 a number of changes to foreigner-related laws passed the parliament. The most important reform was concerned with a quicker expulsion of foreigners who committed crimes, whereas the law regulating German citizenship, which originated from the year 1913, remained unchanged. Furthermore, the German government signed a refugee repatriation agreement with Yugoslavia (Serbia and Montenegro) and the repatriation of the Bosnian civil war refugees began. The German interior minister, Manfred Kanther, declared that the repatriation endeavors underscore the fact that Germany is not an immigration country.

The Federal Office for the Protection of the Constitution (Bundesamt für Verfassungschutz, BfV) reported 8,730 far-right offences (cf. BFV (1997)), of which more than 2,200 were against foreigners and more than 800 had an antisemitic background. Overall, registered offences increased compared to 1994 and 1995, whereas offences with an antisemitic background decreased compared to these years. The most severe incident was the arson attack in Lübeck on January, 18th against a house in which asylum seekers lived and ten lifes were lost. The perpetrators of this attack are still unknown.

In the public debate a series of violent crimes against German tourists and foreigners in Mecklenburg-Vorpommern during the summer months and the dispute on the role of Swiss banks in the second World War received lots of attention. The publication of the book Ordinary Germans: Hitler's Willing Executioners by DANIEL J. Goldhagen in April 1996 set off a heavy debate on the role of the German population in the mass murder of European Jews. In a report to German embassies in the former Soviet Union, the federal office warned of unlimited immigration of Jews to Germany talking about some hundred thousand people planning to apply for immigration to Germany. The minister for economic co-operation and development, Carl-Dieter Spranger (CSU), claimed that 
800,000 Jews were willing to emigrate and that this would cause the German pension system to collapse (cf. JPR (1997)).

\subsection{Distribution of Attitudes and Descriptive Statistics}

Means and standard deviations of the above described answer categories are reported in Table 1. The shares of answers falling into each category are reported in Table A3 in the appendix. The presentation distinguishes between West and East Germany, to reflect apparent heterogeneity, but also since East Germany is oversampled in the 1996 wave of the $A L L B U S$.

A closer look at the descriptive statistics as well as the distribution of answers reveals that there is considerable variation in respondents' attitudes across the different questions. Questions $Q 1$ to $Q 35$ concern attitudes towards immigrants and foreigners, whereas questions Q36 to Q42 explicitly aim at the perception of Jews. If one does not presume that this variation is simply noise, but that there is at least some information contained in it, then it is inevitable to analyze the complete set of questions and not only some of them, e.g. the "classical prejudice" questions, like it is done in many other studies using this dataset. The means of the answers are close to the medium category but there is a statistically significant difference from it in almost all cases.

Coding A and Coding B denote the two constructed answer categories described in the preceding section. The questions $Q 1$ to $Q 4$ are the items for which the original answer categories were on a three-possibilities scale. Therefore, the mean and standard deviation of these questions remain unaffected by the change in coding. For the remaining questions $Q 5$ to $Q 42$ the alternative coding system $B$ increases the standard deviations of the answers. However, the mean answers change in an upward as well as a downward

direction. For 18 questions the means go up, for 19 they go down and for one question it stays constant. 
Table 1: Descriptive Statistics of Attitudes towards Foreigners and Jews

\begin{tabular}{|c|c|c|c|c|}
\hline \multirow[t]{2}{*}{$\overline{\text { QUESTION }}$} & \multicolumn{2}{|c|}{ 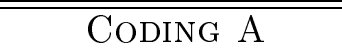 } & \multicolumn{2}{|c|}{ CODING B } \\
\hline & MEAN & Std. Dev. & MEAN & Std. Dev. \\
\hline$\overline{\mathrm{Q} 1}$ & 1.999 & 0.522 & 1.999 & 0.522 \\
\hline Q2 & 2.087 & 0.573 & 2.087 & 0.573 \\
\hline Q3 & 1.964 & 0.678 & 1.964 & 0.678 \\
\hline Q4 & 2.309 & 0.591 & 2.309 & 0.591 \\
\hline Q5 & 2.306 & 0.691 & 2.366 & 0.834 \\
\hline Q6 & 1.854 & 0.755 & 1.810 & 0.876 \\
\hline Q7 & 1.933 & 0.793 & 1.899 & 0.902 \\
\hline Q8 & 1.592 & 0.758 & 1.572 & 0.825 \\
\hline Q9 & 2.052 & 0.721 & 2.074 & 0.891 \\
\hline Q10 & 2.053 & 0.741 & 2.095 & 0.893 \\
\hline Q11 & 1.988 & 0.756 & 1.978 & 0.899 \\
\hline Q12 & 2.019 & 0.764 & 2.050 & 0.886 \\
\hline Q13 & 1.891 & 0.704 & 1.799 & 0.874 \\
\hline Q14 & 2.061 & 0.713 & 2.047 & 0.884 \\
\hline Q15 & 1.997 & 0.724 & 1.959 & 0.872 \\
\hline Q16 & 2.178 & 0.805 & 2.224 & 0.910 \\
\hline Q17 & 2.316 & 0.725 & 2.382 & 0.837 \\
\hline Q18 & 1.312 & 0.563 & 1.270 & 0.610 \\
\hline Q19 & 2.756 & 0.528 & 2.800 & 0.555 \\
\hline Q20 & 2.599 & 0.622 & 2.688 & 0.649 \\
\hline Q21 & 2.223 & 0.829 & 2.206 & 0.917 \\
\hline Q22 & 1.864 & 0.766 & 1.857 & 0.891 \\
\hline Q23 & 2.125 & 0.818 & 2.125 & 0.920 \\
\hline Q24 & 1.731 & 0.527 & 1.608 & 0.636 \\
\hline Q25 & 1.862 & 0.533 & 1.799 & 0.716 \\
\hline Q26 & 2.239 & 0.585 & 2.339 & 0.718 \\
\hline Q27 & 2.084 & 0.572 & 2.123 & 0.765 \\
\hline Q28 & 1.905 & 0.555 & 1.860 & 0.738 \\
\hline Q29 & 2.001 & 0.542 & 2.005 & 0.742 \\
\hline Q30 & 2.392 & 0.593 & 2.502 & 0.669 \\
\hline Q31 & 2.313 & 0.603 & 2.424 & 0.706 \\
\hline Q32 & 1.781 & 0.710 & 1.741 & 0.863 \\
\hline Q33 & 1.733 & 0.705 & 1.699 & 0.854 \\
\hline Q34 & 2.364 & 0.688 & 2.442 & 0.799 \\
\hline Q35 & 2.059 & 0.730 & 2.081 & 0.891 \\
\hline Q36 & 1.791 & 0.544 & 1.721 & 0.648 \\
\hline Q37 & 2.011 & 0.572 & 2.023 & 0.712 \\
\hline Q38 & 1.618 & 0.706 & 1.587 & 0.807 \\
\hline Q39 & 1.681 & 0.701 & 1.670 & 0.822 \\
\hline Q40 & 1.387 & 0.637 & 1.324 & 0.674 \\
\hline Q41 & 2.060 & 0.745 & 2.104 & 0.878 \\
\hline Q42 & 1.488 & 0.650 & 1.483 & 0.754 \\
\hline
\end{tabular}

For a description of the questions see Table A1 in the appendix. Total number of Observations: 2834; 1844 in West Germany and 990 in East Germany. 
Table 2 reports descriptive statistics for the utilized explanatory variables for East and West German respondents. All variables are categorical ${ }^{2}$, except the variable Age. The explanatory variable Fears Loss of Employment is a dummy variable taking the value of one if the individual reported to be afraid of losing his or her job and zero otherwise. Table 2 reveals that slightly more than 11\% of respondents in 1996 were indeed afraid of a job loss. However, this fear was considerably higher in the eastern part of Germany (nearly 18\%) than in the western part (around 8\%). This variable is the only explanatory variable in our analysis which reflects an opinion or personal expectation, all other variables are measured socio-economic characteristics. Its inclusion aims at capturing the unique situation of more than 4 million people registered as unemployed in 1996.

Table 2: Descriptive Statistics of Socio-Economic Variables

\begin{tabular}{l|cc||cc}
\hline \hline ExPlanATORY & \multicolumn{2}{|c|}{ EAst } & \multicolumn{2}{c}{ WEST } \\
VARIABlE & Mean & Std. Dev. & Mean & Std. Dev. \\
\hline Female & 0.511 & 0.500 & 0.488 & 0.500 \\
High Education & 0.177 & 0.382 & 0.254 & 0.436 \\
Medium Education & 0.400 & 0.490 & 0.251 & 0.434 \\
Academic & 0.129 & 0.336 & 0.131 & 0.337 \\
No Formal Training & 0.079 & 0.270 & 0.155 & 0.362 \\
Fears Loss of Employment & 0.176 & 0.381 & 0.079 & 0.270 \\
Not Employed & 0.056 & 0.229 & 0.014 & 0.118 \\
Married & 0.667 & 0.472 & 0.623 & 0.485 \\
Low Share of Foreigners & 0.937 & 0.242 & 0.082 & 0.274 \\
Age & 47.39 & 16.48 & 45.490 & 16.73 \\
Number of observations & \multicolumn{3}{|c|}{990} & \multicolumn{2}{c}{1,844} \\
\hline \hline
\end{tabular}

Table 2 shows that respondents residing in East Germany on average report an slightly higher education level (the share of respondents reporting a low education level is around $43 \%$ in East and around $50 \%$ in West Germany) and a considerably lower share of East Germans report to have no formal training. On the other hand, a substantially higher share of East Germans are not employed. Moreover, a very high share of East German respondents live in a region with a below-average foreigner share.

We introduced the variable Low Share of Foreigners as a measure of possible contacts to foreigners. There exists a question on contacts with foreigners in the ALLBUS and more than half of the respondents in the 1996 wave report to have them in either family, neighborhood, among friends or at work. However, the intensity of these contacts remains unclear. Therefore, we decided to use a measure of exposure to foreigners, i.e. the actual share of foreigners living in the region (Landkreis) of the respondent as a natural indicator for possible contacts to foreigners. We would presume that this indication reflects the possible information of the respondent concerning foreigners. This variable takes the value of one if the respondent lives in a region with less that $8 \%$ foreigner share (the nation-wide foreigner share) and zero otherwise.

We would expect that the contact with immigrants reduces xenophobic misperceptions and would, therefore, expect a more positive attitude towards foreigners for those

\footnotetext{
${ }^{2}$ For a description of the explanatory variables see Table A4 in the appendix.
} 
individuals not living in a region with a low foreigner share. However, this variable may be endogenous if foreigners decide to live in regions where natives have a more positive perception of them. Usually, the residential choice of individuals is determined by a complex set of factors, including family relations, friends, labor market opportunities and local amenities. It is possible that for foreigners the perception by natives may contribute to the local amenities of candidate locations of residence, but it seems to be only one element out of a set of several factors. Therefore, we would expect that the endogeneity of this variable is not severe. Specifically, new immigrants will probably display a low likelihood to move to rural East Germany for reasons of economic opportunity alone.

As already mentioned in section 2, there is a possibly severe endogeneity problem of many of the variables typically used as explanatory factors in empirical studies on attitudes towards minority groups. It seems quite natural to suspect that the perception of foreigners or Jews is not independent from individual opinions towards e.g. politics, religion or the role of the family. However, a priori the direction of causality is completely unclear. We would presume that opinions towards several aspects of society are indeed interrelated. The simultaneity of opinion forming, however, does prevent us from using expressed opinions towards e.g. politics as explanatory variables.

In addition to the possible endogeneity or simultaneity of opinions, the possibility of unobserved heterogeneity may bias estimation results as well. For instance, the unobservable ability to reflect about one's own way of living may be correlated with the expressed attitudes towards minorities but it may also be correlated with the decision on the level of education. The usual approach to handle problems like this one is to instrument the correlated variable. In the case at hand, however, we have good reason to abstain from such an approach. First, in the current context - all variables on the left-hand side are latent - any valid instrumental variable will have a difficult time unfolding its potential. Second, even in the absence of the conceptual problems characterizing the extraction of latent factors from categorical observables a valid instrument is difficult to find. Thus, we proceed under the maintained assumption of exogeneity of the right-hand side variables.

\subsection{Reduced Form Results}

As a first step we perform an independent ordered probit analysis for each of the 35 questions on the perception of foreigners and each of the seven questions on the perception of Jews, summarized in the last subsection and described in more detail in the appendix. For this purpose, we utilized the explanatory variables described in Table 2 and Table A4 with one exception. Since only a small fraction of respondents reported not to be employed we combined the variables Not Employed and Fears Loss of Employment together in the variable Labor Market. Therefore, this new variable takes the value of 1 if the individual reported either to be not employed or to be afraid of loosing her or his job, and zero otherwise.

Estimation results of the reduced-form parameters exhibit noticeably stable results. These results are summarized ${ }^{3}$ in Table 3 for the questions on the perception of foreign-

\footnotetext{
${ }^{3} \mathrm{~A}$ complete list of reduced form results is available by the authors upon request.
} 
ers and in Table 4 for the attitudes towards Jews. Since the estimated coefficients of an ordered probit model are not interpretable straightforwardly, because they do not concur with the marginal effects of the explanatory variables, we report only the direction of influence and its statistical significance. Since the coding of the dependent variables is "0" for a positive attitude and " 2 " for a negative attitude, a "+" denotes a statistically significant positive impact, i.e. a more negative attitude. Consequently, a "-" denotes a statistically significant negative impact, i.e. a more positive attitude.

On balance, East German respondents tend to display a slightly more negative attitude towards foreigners. Individuals with medium or even high education clearly tend to answer more favorably (our maintained hypothesis is that this reflects a genuine difference in preferences and perceptions, not a strategic way to answer to the questions), as do academics. On the other hand, respondents with no formal training tend to answer in a more negative fashion, as do, more moderately, those respondents who experience employment problems. Interestingly, a low foreigner share is often associated with a more negative attitude. No clear tendency emerges for the distinction between male and female respondents and for marital status, while there seems to be some, albeit minor, heterogeneity across different age groups. 
Table 3: Reduced-Form Results on Intensity of Negative Attitude - Questions on Foreigners

\begin{tabular}{|c|c|c|c|c|c|c|c|c|c|c|c|c|}
\hline \multirow{2}{*}{$\begin{array}{l}\text { EXPLANATORY } \\
\text { VARIABLE }\end{array}$} & \multicolumn{12}{|c|}{ "Dependent Variable; Coding A } \\
\hline & Q1 & Q2 & Q3 & Q4 & Q5 & Q6 & Q7 & Q8 & Q9 & Q10 & Q11 & $\overline{\text { Q12 }}$ \\
\hline East Germany & + & 0 & + & + & 0 & + & 0 & 0 & + & - & + & + \\
\hline Female & 0 & 0 & 0 & 0 & 0 & 0 & 0 & 0 & + & 0 & + & 0 \\
\hline High Education & - & - & - & - & - & - & - & - & - & - & - & - \\
\hline Medium Education & - & - & - & - & - & - & - & - & - & - & - & 0 \\
\hline No Formal Training & 0 & + & + & + & 0 & + & 0 & + & 0 & 0 & + & 0 \\
\hline Academic & 0 & 0 & - & - & 0 & 0 & - & - & - & - & 0 & 0 \\
\hline Labor Market & 0 & 0 & 0 & + & 0 & + & 0 & 0 & 0 & 0 & + & 0 \\
\hline Married & 0 & 0 & 0 & 0 & + & 0 & 0 & 0 & 0 & 0 & 0 & 0 \\
\hline Low Foreigner Share & 0 & + & 0 & 0 & + & 0 & 0 & + & + & 0 & + & 0 \\
\hline Age & + & + & 0 & + & + & 0 & 0 & + & 0 & 0 & 0 & 0 \\
\hline Age Squared & - & 0 & 0 & - & 0 & 0 & 0 & 0 & 0 & 0 & + & 0 \\
\hline $\begin{array}{l}\text { EXPLANATORY } \\
\text { VARIABLE }\end{array}$ & \multicolumn{12}{|c|}{ "Dependent Variable; Coding B } \\
\hline East Germany & + & 0 & + & + & 0 & + & 0 & + & + & - & + & + \\
\hline Female & 0 & 0 & + & 0 & 0 & 0 & 0 & 0 & + & + & + & 0 \\
\hline High Education & - & - & - & - & - & - & - & - & - & - & - & - \\
\hline Medium Education & - & - & - & - & - & - & - & - & - & - & - & 0 \\
\hline No Formal Training & 0 & + & + & + & + & + & + & + & 0 & 0 & 0 & 0 \\
\hline Academic & 0 & 0 & - & - & 0 & - & - & - & 0 & - & 0 & 0 \\
\hline Labor Market & 0 & 0 & 0 & + & 0 & 0 & 0 & 0 & 0 & + & + & 0 \\
\hline Married & 0 & 0 & 0 & 0 & + & 0 & 0 & - & 0 & 0 & 0 & 0 \\
\hline Low Foreigner Share & 0 & + & 0 & 0 & 0 & 0 & 0 & + & 0 & 0 & + & 0 \\
\hline Age & + & + & 0 & + & 0 & 0 & 0 & + & 0 & 0 & 0 & 0 \\
\hline Age Squared & - & 0 & 0 & - & 0 & 0 & 0 & 0 & 0 & 0 & 0 & 0 \\
\hline
\end{tabular}

On a $95 \%$ significance level: "+" denotes a statistically significant positive,

"-" a statistically significant negative, and "0" a statistically insignificant impact.

The most important changes due to the alternative coding system for Q5 to Q12 are: The variable Low Foreigner Share becomes insignificant in Q5 and Q9, the variable Labor Market becomes significantly positive in Q10, the variable No Formal Training becomes significantly positive in $Q 5$ and $Q 7$, but insignificant in $Q 11$ and the variable East Germany becomes significantly positive in $Q 8$. 
Table 3 continued: Reduced Form Results on Intensity of Negative Attitude - Questions on Foreigners

\begin{tabular}{|c|c|c|c|c|c|c|c|c|c|c|c|c|}
\hline \multirow{2}{*}{$\begin{array}{l}\text { EXPLANATORY } \\
\text { VARIABLE }\end{array}$} & \multicolumn{12}{|c|}{ "DePendent Variable; Coding A } \\
\hline & Q13 & Q14 & Q15 & Q16 & Q17 & Q18 & Q19 & Q20 & Q21 & Q22 & Q23 & Q24 \\
\hline East Germany & 0 & 0 & 0 & 0 & 0 & - & + & 0 & 0 & 0 & - & + \\
\hline Female & - & 0 & 0 & 0 & + & 0 & 0 & 0 & - & 0 & - & - \\
\hline High Education & - & - & - & - & - & - & 0 & - & - & - & - & - \\
\hline Medium Education & 0 & - & - & - & - & 0 & 0 & - & - & 0 & - & 0 \\
\hline No Formal Training & - & 0 & 0 & + & 0 & 0 & 0 & 0 & 0 & 0 & 0 & + \\
\hline Academic & 0 & - & - & 0 & 0 & 0 & - & - & - & 0 & - & 0 \\
\hline Labor Market & + & + & 0 & 0 & + & 0 & 0 & 0 & + & 0 & 0 & + \\
\hline Married & 0 & 0 & 0 & 0 & 0 & 0 & + & 0 & 0 & 0 & 0 & - \\
\hline Low Foreigner Share & 0 & + & + & + & 0 & + & 0 & 0 & + & 0 & + & 0 \\
\hline Age & 0 & 0 & - & 0 & 0 & 0 & 0 & 0 & 0 & 0 & 0 & 0 \\
\hline Age Squared & 0 & 0 & + & + & 0 & 0 & 0 & 0 & 0 & + & 0 & 0 \\
\hline $\begin{array}{l}\text { EXPLANATORY } \\
\text { VARIABLE }\end{array}$ & \multicolumn{12}{|c|}{ Dependent Variable; Coding B } \\
\hline East Germany & 0 & 0 & 0 & 0 & - & - & 0 & 0 & 0 & 0 & - & + \\
\hline Female & - & 0 & 0 & 0 & + & 0 & 0 & 0 & - & 0 & - & 0 \\
\hline High Education & - & - & - & - & - & - & 0 & - & - & - & - & 0 \\
\hline Medium Education & 0 & - & - & - & - & 0 & 0 & - & - & 0 & - & 0 \\
\hline No Formal Training & 0 & 0 & 0 & 0 & 0 & 0 & 0 & 0 & 0 & 0 & 0 & + \\
\hline Academic & - & - & - & 0 & 0 & 0 & 0 & - & - & 0 & - & 0 \\
\hline Labor Market & + & 0 & 0 & 0 & + & 0 & 0 & 0 & + & 0 & 0 & 0 \\
\hline Married & 0 & 0 & 0 & 0 & 0 & 0 & 0 & 0 & 0 & 0 & 0 & - \\
\hline Low Foreigner Share & 0 & + & + & 0 & 0 & + & 0 & 0 & + & 0 & + & 0 \\
\hline Age & 0 & 0 & - & 0 & 0 & 0 & 0 & 0 & 0 & 0 & 0 & 0 \\
\hline Age Squared & 0 & 0 & + & + & 0 & 0 & 0 & 0 & 0 & + & 0 & 0 \\
\hline
\end{tabular}

On a $95 \%$ significance level: "+" denotes a statistically significant positive,

"_" a statistically significant negative, and "0" a statistically insignificant impact.

The most important changes due to the alternative coding system for Q13 to Q24 are: The variable East Germany becomes significantly negative in Q1\%, but insignificant in Q19. The variable No Formal Training becomes insignificant in Q13 and Q16, whereas Academic becomes insignificant in Q19, but significantly negative in $Q 13$. The variables Labor Market and Low Foreigner Share become insignificant in Q14/Q24 and Q16, respectively. Please note that in the coding system $B$ no explanatory variable has a statistically significant impact on the distribution of answers in $Q 19$. 
Table 3 continued: Reduced-Form Results on Intensity of Negative Attitude - Questions on Foreigners

\begin{tabular}{|c|c|c|c|c|c|c|c|c|c|c|c|}
\hline \multirow{2}{*}{$\begin{array}{l}\text { EXPLANATORY } \\
\text { VARIABLE }\end{array}$} & \multicolumn{11}{|c|}{ DEPEndent Variable; Coding A } \\
\hline & Q25 & Q26 & Q27 & Q28 & Q29 & Q30 & Q31 & Q32 & Q33 & Q34 & Q35 \\
\hline East Germany & + & + & + & + & + & 0 & + & 0 & + & - & - \\
\hline Female & - & - & 0 & - & 0 & - & 0 & 0 & 0 & - & 0 \\
\hline High Education & - & - & - & - & - & - & - & - & - & - & - \\
\hline Medium Education & 0 & 0 & - & - & - & - & - & 0 & - & - & - \\
\hline No Formal Training & 0 & + & + & + & + & 0 & + & + & 0 & 0 & 0 \\
\hline Academic & - & 0 & 0 & 0 & - & 0 & 0 & 0 & 0 & 0 & 0 \\
\hline Labor Market & 0 & 0 & 0 & + & 0 & 0 & + & 0 & 0 & 0 & 0 \\
\hline Married & - & 0 & 0 & 0 & 0 & 0 & 0 & 0 & 0 & 0 & 0 \\
\hline Low Foreigner Share & - & - & 0 & + & 0 & 0 & 0 & 0 & 0 & 0 & + \\
\hline Age & 0 & 0 & 0 & 0 & + & + & 0 & 0 & 0 & 0 & 0 \\
\hline Age Squared & 0 & 0 & 0 & 0 & 0 & 0 & 0 & 0 & 0 & 0 & 0 \\
\hline $\begin{array}{l}\text { EXPLANATORY } \\
\text { VARIABLE }\end{array}$ & \multicolumn{11}{|c|}{ "DEPEndent Variable; Coding B } \\
\hline East Germany & + & + & + & + & + & 0 & 0 & 0 & + & - & 0 \\
\hline Female & - & - & 0 & - & - & - & 0 & 0 & 0 & - & 0 \\
\hline High Education & - & - & - & - & - & - & - & - & - & - & - \\
\hline Medium Education & 0 & 0 & - & - & 0 & 0 & 0 & - & - & 0 & - \\
\hline No Formal Training & 0 & 0 & + & + & + & + & + & 0 & 0 & 0 & 0 \\
\hline Academic & 0 & - & 0 & - & 0 & 0 & 0 & 0 & 0 & 0 & 0 \\
\hline Labor Market & 0 & 0 & 0 & + & 0 & 0 & 0 & 0 & 0 & 0 & + \\
\hline Married & - & 0 & 0 & 0 & 0 & 0 & 0 & 0 & 0 & 0 & 0 \\
\hline Low Foreigner Share & - & - & 0 & 0 & 0 & 0 & 0 & 0 & 0 & 0 & 0 \\
\hline Age & 0 & 0 & 0 & 0 & + & 0 & 0 & 0 & 0 & 0 & 0 \\
\hline Age Squared & 0 & 0 & + & 0 & - & 0 & 0 & 0 & 0 & 0 & 0 \\
\hline
\end{tabular}

On a $95 \%$ significance level: "+" denotes a statistically significant positive,

"-" a statistically significant negative, and "0" a statistically insignificant impact.

The most important changes due to the alternative coding system for Q25 to Q35 are: The variables East Germany, Medium Education and Low Foreigner Share become insignificant in Q31/Q35, Q29 / Q30 / Q31 / Q34 and Q28 /Q35, respectively. The variable No Formal Training becomes significantly positive in Q30, but insignificant in Q26 and Q32. Finally, the variable Academic becomes significantly negative in Q26 and Q28, but insignificant in Q25 and Q29.

All in all, there is no dramatical change due to the coding system. For almost all questions, irrespective of the coding system of the dependent variables, respondents with a high or medium education display a statistically significant more positive attitude, whereas respondents with no formal training tend to have a statistically significant more negative attitude towards foreigners. Respondents with an academic background also tend to have a more positive attitude, whereas the evidence for the effect of the respondents' geographical residence as well as his or her age and gender is mixed. The effect of a low foreigner share in the region in which the respondent lives is also mixed, although it tends towards a more negative attitude. Finally, the influence of the labor market variable tends towards a more negative attitude as well, although this variable is often statistically 
insignificant.

Table 4: Reduced-Form Results on Intensity of Negative Attitude - Questions on Jews

\begin{tabular}{|c|c|c|c|c|c|c|c|}
\hline EXPLANATORY VARIABLE & \multicolumn{7}{|c|}{ DEependent VARiable; Coding A } \\
\hline & Q36 & Q37 & Q38 & Q39 & $\mathrm{Q} 40$ & Q41 & Q42 \\
\hline East Germany & + & + & 0 & 0 & - & - & 0 \\
\hline Female & - & - & 0 & - & - & - & 0 \\
\hline High Education & - & - & - & - & - & - & - \\
\hline Medium Education & - & - & - & - & - & - & - \\
\hline No Formal Training & + & + & + & 0 & 0 & 0 & + \\
\hline Academic & 0 & 0 & 0 & 0 & - & - & 0 \\
\hline Labor Market & + & 0 & 0 & 0 & 0 & 0 & 0 \\
\hline Married & 0 & 0 & 0 & 0 & 0 & 0 & 0 \\
\hline Low Foreigner Share & 0 & 0 & 0 & 0 & 0 & 0 & 0 \\
\hline Age & 0 & + & 0 & + & 0 & + & + \\
\hline Age Squared & 0 & 0 & 0 & 0 & 0 & 0 & 0 \\
\hline EXPLANATORY VARIABLE & \multicolumn{7}{|c|}{ Dependent VARIABLe; Coding B } \\
\hline East Germany & 0 & + & + & 0 & 0 & - & 0 \\
\hline Female & 0 & - & - & 0 & - & - & 0 \\
\hline High Education & - & - & - & - & 0 & - & - \\
\hline Medium Education & - & - & - & - & 0 & - & - \\
\hline No Formal Training & + & 0 & + & 0 & 0 & 0 & + \\
\hline Academic & 0 & 0 & 0 & 0 & - & - & 0 \\
\hline Labor Market & 0 & 0 & 0 & 0 & 0 & 0 & 0 \\
\hline Married & 0 & 0 & 0 & 0 & 0 & 0 & 0 \\
\hline Low Foreigner Share & 0 & 0 & 0 & 0 & 0 & 0 & 0 \\
\hline Age & + & 0 & 0 & 0 & 0 & + & + \\
\hline Age Squared & 0 & 0 & 0 & 0 & 0 & 0 & - \\
\hline
\end{tabular}

On a $95 \%$ significance level: "+" denotes a statistically significant positive, "-" a statistically significant negative, and "0" a statistically insignificant impact.

Table 4 reports the impact of the estimated reduced form coefficients on the seven questions on the the perception of Jews. For these questions the picture concerning the education and training variables remains unchanged. However, the share of foreigners as well as the labor market variable display no statistically significant effect. Females tend to have a more positive attitude towards Jews than do men, whereas the evidence for the impact of living in East Germany is completely mixed.

In both the analysis of the perception of foreigners and of Jews the reduced-form results are widely consistent, yet quite heterogenous. Therefore, no further interpretation is possible without imposing more structure on the results. Thus, in order to receive a more comprehensive picture on the determinants of the perception of foreigners and Jews we present the results of the structural parameters. 


\subsection{The Structural Parameters}

The structural parameters $\gamma_{k}(k=1, \ldots, K)$ are identified by our empirical strategy outlined in section 3.3, retaining a separation between the two principal sets of questions. Estimation results are presented in Table 5a for the foreigner-related questions and in Table $\mathbf{5 b}$ for the questions on the perception of Jews.

Table 5a: Structural Parameters - Questions on Foreigners

\begin{tabular}{l|cc||cc}
\hline \hline Explan ATORY VARIABLE & \multicolumn{2}{|c}{ CoDing A } & \multicolumn{2}{c}{ CoDING B } \\
& coefficient & t-value & coefficient & t-value \\
\hline \hline East Germany & 0.13507 & 1.00 & 0.11557 & 0.83 \\
Female & -0.01771 & 0.39 & -0.01677 & 0.36 \\
High Education & -0.38493 & 5.10 & -0.36638 & 4.70 \\
Medium Education & -0.16436 & 2.92 & -0.14984 & 2.56 \\
No Formal Training & 0.10983 & 1.55 & 0.09324 & 1.29 \\
Academic & -0.16202 & 1.88 & -0.15603 & 1.74 \\
Labor Market & 0.10126 & 1.50 & 0.09146 & 1.32 \\
Married & 0.02804 & 0.54 & 0.01782 & 0.33 \\
Low Foreigner Share & 0.06272 & 0.73 & 0.07088 & 0.80 \\
Age & 0.00529 & 0.62 & 0.00396 & 0.45 \\
Age Squared & 0.00004 & 0.00 & 0.00004 & 0.00 \\
\hline \hline
\end{tabular}

The estimated coefficients suggest that only the education categories exhibit a statistically significant impact on the distribution of agreement/disagreement by native respondents. Individuals with a high education degree have a significantly more positive attitude towards foreigners than people with a low education level. This variable exhibits the strongest impact on the answers of respondents. The labor market variable as well as our proximity measure to model possible contacts to foreigners do not display a statistically significant impact on the usual $95 \%$ significance level. These results are different from what one would conclude from an analysis of single or selected questions alone and they are independent of the coding of the answer categories.

Table 5b: Structural Parameters - Questions on Jews

\begin{tabular}{l|cc||cc}
\hline \hline ExPlanATORY VARIABLE & \multicolumn{2}{|c}{ CoDING A } & \multicolumn{2}{c}{ CoDING B } \\
& coefficient & t-value & coefficient & t-value \\
\hline \hline East Germany & -0.02700 & 0.30 & -0.03432 & 0.40 \\
Female & -0.11859 & 2.61 & -0.11801 & 2.57 \\
High Education & -0.42447 & 5.36 & -0.37465 & 4.70 \\
Medium Education & -0.18029 & 3.32 & -0.15810 & 2.84 \\
No Formal Training & 0.10454 & 1.53 & 0.07339 & 1.02 \\
Academic & -0.13720 & 1.54 & -0.13925 & 1.49 \\
Labor Market & 0.06509 & 0.94 & 0.05571 & 0.82 \\
Married & -0.04505 & 0.88 & -0.03532 & 0.66 \\
Low Foreigner Share & -0.06168 & 0.70 & -0.06165 & 0.75 \\
Age & 0.01266 & 1.47 & 0.01357 & 1.57 \\
Age Squared & -0.00007 & 0.81 & -0.00009 & 1.05 \\
\hline \hline
\end{tabular}


This picture does not change very much if the attitudes towards Jews in Germany are concerned. In contrast to the results for the perception of foreigners the gender of respondents plays a decisive role in explaining the unobserved component of the perception of Jews. Women tend to have a statistically significant more positive attitude than men. Again the education of the respondents has the largest impact on their answers. All other explanatory variables are far away from being statistically significant.

Therefore, if the information contained in the distribution of answers to a variety of related opinion questions is utilized, the decisive factor driving the common unobserved component of the perception of foreigners and Jews is education. This has important implications for the design of possible interventions aiming at a more positive perception of minorities. Our results suggest that more education on average would change preferences and perceptions positively. However, in such an altered environment a higher average level of education would manifest itself again in the constants of each reduced-form equation, i.e. in the $\delta_{0}^{j}$ s. This means that for the part of the population with more education the average $\delta_{0}^{j}$ would decrease, retaining the original differential between the low and the high educated. Any other change in coefficients would require that the structure is altered altogether. Therefore, no change in structural coefficients arises from an increase in education, since we are only able to measure the effect of the latent variable relative to its own average.

\section{Conclusions}

This paper offered a comprehensive analysis of the opinions collected by the 1996 wave of a large German opinion survey, the $A L L B U S$. To this end, we developed a model explaining the answers of native respondents on a large set of questions in an interdependent framework. In this framework it is assumed that all questions utilized are able to "extract" the true, but unobservable overall perception of foreigners and that this unobservable overall perception can in turn be explained by a set of observable socio-economic characteristics. This analysis, therefore, assumes that all utilized questions are, in principle, able to "extract" the true opinion of respondents, although to varying degree. To achieve this aim, we have to forego all attempts to extract the level of xenophobia or antisemitism in a population of respondents, though. All attempts at such an analysis in a single-country study must fail.

In order to identify the structural parameters of the model we invoked a set of identification assumptions which are non-testable and which have to be assumed to hold true a priori. The estimation results for the structural coefficients derived on the basis of our identification assumptions suggest quite different conclusions on the explanatory power of observable socio-economic characteristics than what one would conclude from the (reduced form) analysis of a single question alone. Essentially, the only variable able to reliably explain the heterogeneity of the unobserved component of the perception of foreigners and Jews among native Germans to is the level of individual education. Popular suggestions for an explanation of negative attitudes towards minorities like the labor market situation of a respondent or his/her age turn out to be insignificant as soon as one is willing to analyze all relevant questions. 
The implications of these results are twofold. Firstly, one may hypothesize that the reason for this finding is the incoherent opinion of respondents towards minorities. That is, it might be possible that individual respondents do not answer in a coherent way to all the questions in the $A L L B U S$. Secondly, if one is willing to put confidence in our framework of analysis and the identification assumptions invoked then one would conclude that misconceptions of minorities as well as a negative perception of such groups can be reduced by comprehensive education programs and initiatives.

Clearly, for the success of an immigration policy aiming at the attraction of highskilled migrants from all over the world, it is important to employ measures that are able to enhance the perception of foreigners in Germany. Therefore, such education programs and initiatives could be helpful. However, the success of such activities is far from being guaranteed. To analyze whether and to what extent education is really able to resolve misperceptions and to reduce negative attitudes will be one of the key challenges of this line of research. A comprehensive scientific evaluation of this question as well as the effectiveness of other integration measures is one of the central issues of future research in this field. 


\section{References}

Adorno, Theodor W., Else Frenkel-Brunswick, Daniel J. Levinson and R. Nevitt Sanford (1950), The Authoritarian Personality. New York: Harper.

Alba, Richard, Peter Schmidt and Martina Wasmer (2000), Deutsche und Ausländer: Freunde, Fremde oder Feinde? Wiesbaden: Westdeutscher Verlag.

Bauer, Thomas K., Magnus Lofstrom and Klaus F. Zimmermann (2000), Immigration Policy, Assimilation of Immigrants and Natives' Sentiments Towards Immigrants: Evidence From 12 OECD-Countries. Swedish Economic Policy Review, 7, 11-53.

Benz, Wolfgang (ED.) (1992 ff), Jahrbuch für Antisemitismusforschung. Frankfurt/New York: Campus Verlag.

Bergmann, Werner and Rainer Erb (2000), Antisemitismus in der Bundesrepublik Deutschland 1996. In: Alba, Richard, Peter Schmidt and Martina WasMER (EDS.), Deutsche und Ausländer: Freunde, Fremde oder Feinde? Wiesbaden: Westdeutscher Verlag, 439-483.

Bundesamt Für Verfassungschutz (1997), Verfassungsschutzbericht 1996. Bonn.

Dustmann, Christian and Ian Preston (2000A), Attitudes to Ethnic Minorities, Ethnic Context and Location Decisions. Economic Journal, 111, 353 - 373.

Dustmann, Christian and Ian Preston (2000B), Racial and Economic Factors in Attitudes to Immigration. IZA Discussion Paper No. 190.

Fertig, Michael and Christoph M. Schmidt (2001), First- and Second-Generation Migrants - What Do We Know and What Do People Think. In: RotTe, RAlph (ED.), Migration Policy and the Economy: International Experiences (forthcoming).

Fischer, Arthur, Yvonne Fritzsche, Werner Fuchs-Heinritz and Richard MünCHMEIER (2000), Jugend 2000 - 13.Shell Jugendstudie. Leske \& Budrich.

Fishbein, Martin and ICEK Aijzen (1975), Belief, Attitude, Intention and Behavior. An Introduction to Theory and Research. Reading: Addison Wesley.

GAng, Ira N. and Francisco L. Rivera-Batiz (1994), Unemployment and Attitudes Towards Foreigners in Germany. In: Steinmann, Gunter and Ralf E. Ulrich (EDS.), The Economic Consequences of Immigration to Germany, Heidelberg: PhysicaVerlag, 121-154.

Institute for Jewish Policy Research (JPR) (1997), Antisemitism World Report 199\%, London.

Lüdemann, Christian (2000), Die Erklärung diskriminierender Einstellungen gegenüber Ausländern, Juden und Gastarbeitern in Deutschland - Eine Test der allgemeinen 
Attitüdentheorie von Fishbein. In: Alba, Richard, Peter Schmidt and Martina Wasmer (EDs.), Deutsche und Ausländer: Freunde, Fremde oder Feinde? Wiesbaden: Westdeutscher Verlag, 439-483.

Schmidt, Peter and Aribert Heyder (2000), Wer neigt eher zu autoritärer Einstellung und Ethnozentrismus, die Ost- oder die Westdeutschen? - Eine Analyse mit Strukturgleichungsmodellen. In: Alba, Richard, Peter Schmidt and Martina WASMER (EDS.), Deutsche und Ausländer: Freunde, Fremde oder Feinde? Wiesbaden: Westdeutscher Verlag, 439-483.

Sumner, William Graham (1906), Folkways. A Study of the Sociological Importance of Usages, Manners, Customs, Mores, and Morals. Boston: Ginn. 
Table A1: Description of ALLBUS Questions on Attitudes Towards Minorities

\begin{tabular}{|c|c|}
\hline VARIABLE & "DESCRIPTION \\
\hline & Unlimited, limited or no immigration of \\
\hline Q1 & Ethnic Germans \\
\hline Q2 & Asylum seekers \\
\hline Q3 & Workers from EU-countries \\
\hline \multirow[t]{2}{*}{ Q4 } & Workers from Non-EU-countries \\
\hline & Should foreigners in Germany \\
\hline Q5 & Assimilate more to the German way of life? \\
\hline Q6 & Be sent back if unemployment is high? \\
\hline Q7 & Prohibited from political activity in Germany? \\
\hline \multirow[t]{2}{*}{ Q8 } & Marry among themselves? \\
\hline & Foreigners in Germany \\
\hline Q9 & Are a burden for the social security system. \\
\hline Q10 & Are a burden for the housing market. \\
\hline Q11 & Take jobs away. \\
\hline Q12 & Commit more crimes. \\
\hline Q13 & Do the awkward jobs Germans would not do. \\
\hline Q14 & Contribute to the variety of culture in Germany. \\
\hline \multirow[t]{2}{*}{ Q15 } & Contribute to the pension system. \\
\hline & Important criterions for German citizenship should be \\
\hline Q16 & German descent. \\
\hline Q17 & Assimilation to the German way of life. \\
\hline Q18 & Membership in a Christian church. \\
\hline Q19 & Non-commitment of crimes. \\
\hline Q20 & Ability to earn one's own living. \\
\hline \multirow[t]{2}{*}{ Q21 } & Would you agree to the possibility to hold a double citizenship? \\
\hline & Should foreigners in Germany \\
\hline Q22 & Receive the same amount of social security benefits? \\
\hline \multirow[t]{2}{*}{ Q23 } & Receive the right to vote on the local/municipal level? \\
\hline & Would you appreciate living in the neighborhood of ...? \\
\hline Q24 & Italians \\
\hline Q25 & Ethnic Germans \\
\hline Q26 & Asylum seekers \\
\hline \multirow[t]{2}{*}{ Q27 } & Turks \\
\hline & Would you appreciate it if a ... marries a member of your family? \\
\hline Q28 & Italian \\
\hline Q29 & Ethnic German \\
\hline Q30 & Asylum seeker \\
\hline \multirow[t]{2}{*}{ Q31 } & Turk \\
\hline & Should ... receive the same rights as native Germans? \\
\hline Q32 & Italians \\
\hline Q33 & Ethnic Germans \\
\hline Q34 & Asylum seekers \\
\hline Q35 & Turks \\
\hline
\end{tabular}

Q1 to Q4 were originally coded on a three answer possibilities scale.

All other questions on a seven answer possibilities sale. See also text. 
Table A2: Description of ALLBUS Questions on Attitudes Towards Jews

\begin{tabular}{l|l}
\hline \hline VARIABLE & DESCRIPTION \\
\hline Q36 & Would you appreciate living in the neighborhood of a Jew? \\
Q37 & Would you appreciate it if a Jew marries a member of your family? \\
Q38 & Should Jews receive the same rights as native Germans? \\
Q39 & Jews have too much influence in the world. \\
Q40 & I feel ashamed of the atrocities Germans committed on Jews. \\
Q41 & Jews exploit German history. \\
Q42 & Jews are not completely innocent of their persecution. \\
\hline \hline
\end{tabular}


Table A3: Distribution of Answers - West vs. East Germany

\begin{tabular}{|c|c|c|c|c|c|c|c|}
\hline \multicolumn{2}{|c|}{ "Question \& REGION } & \multicolumn{3}{|c|}{ CODING $\mathrm{A}$} & \multicolumn{3}{|c|}{ CODING B } \\
\hline & & positive & medium & negative & positive & medium & negative \\
\hline \multirow[t]{2}{*}{ Q1 } & West & $13.99 \%$ & $74.89 \%$ & $11.12 \%$ & $13.99 \%$ & $74.89 \%$ & $11.12 \%$ \\
\hline & East & $12.93 \%$ & $68.89 \%$ & $18.18 \%$ & $12.93 \%$ & $68.89 \%$ & $18.18 \%$ \\
\hline \multirow[t]{2}{*}{ Q2 } & West & $12.91 \%$ & $66.27 \%$ & $20.82 \%$ & $12.91 \%$ & $66.27 \%$ & $20.82 \%$ \\
\hline & East & $11.52 \%$ & $66.77 \%$ & $21.72 \%$ & $11.52 \%$ & $66.77 \%$ & $21.72 \%$ \\
\hline \multirow[t]{2}{*}{ Q3 } & West & $32.27 \%$ & $55.80 \%$ & $11.93 \%$ & $32.27 \%$ & $55.80 \%$ & $11.93 \%$ \\
\hline & East & $10.91 \%$ & $50.51 \%$ & $38.59 \%$ & $10.91 \%$ & $50.51 \%$ & $38.59 \%$ \\
\hline \multirow[t]{2}{*}{ Q4 } & West & $8.19 \%$ & $60.74 \%$ & $31.07 \%$ & $8.19 \%$ & $60.74 \%$ & $31.07 \%$ \\
\hline & East & $4.24 \%$ & $45.76 \%$ & $50.00 \%$ & $4.24 \%$ & $45.76 \%$ & $50.00 \%$ \\
\hline \multirow[t]{2}{*}{ Q5 } & West & $13.99 \%$ & $44.14 \%$ & $41.87 \%$ & $24.19 \%$ & $17.41 \%$ & $58.41 \%$ \\
\hline & East & $11.82 \%$ & $40.81 \%$ & $47.37 \%$ & $21.21 \%$ & $16.46 \%$ & $62.32 \%$ \\
\hline \multirow[t]{2}{*}{ Q6 } & West & $42.84 \%$ & $40.24 \%$ & $16.92 \%$ & $56.18 \%$ & $19.36 \%$ & $24.46 \%$ \\
\hline & East & $25.56 \%$ & $42.32 \%$ & $32.12 \%$ & $37.47 \%$ & $20.30 \%$ & $42.22 \%$ \\
\hline \multirow[t]{2}{*}{ Q7 } & West & $36.39 \%$ & $36.33 \%$ & $27.28 \%$ & $48.16 \%$ & $16.81 \%$ & $35.03 \%$ \\
\hline & East & $32.42 \%$ & $37.27 \%$ & $30.30 \%$ & $42.53 \%$ & $19.29 \%$ & $38.18 \%$ \\
\hline \multirow[t]{2}{*}{ Q8 } & West & $62.47 \%$ & $23.81 \%$ & $13.72 \%$ & $69.52 \%$ & $12.15 \%$ & $18.33 \%$ \\
\hline & East & $48.18 \%$ & $29.70 \%$ & $22.12 \%$ & $55.35 \%$ & $16.36 \%$ & $28.28 \%$ \\
\hline \multirow[t]{2}{*}{ Q9 } & West & $27.71 \%$ & $48.54 \%$ & $23.75 \%$ & $41.87 \%$ & $20.07 \%$ & $38.07 \%$ \\
\hline & East & $15.76 \%$ & $46.16 \%$ & $38.08 \%$ & $25.86 \%$ & $20.10 \%$ & $54.04 \%$ \\
\hline \multirow[t]{2}{*}{ Q10 } & West & $23.21 \%$ & $45.28 \%$ & $31.51 \%$ & $33.79 \%$ & $19.36 \%$ & $46.85 \%$ \\
\hline & East & $28.18 \%$ & $44.04 \%$ & $27.78 \%$ & $38.79 \%$ & $19.70 \%$ & $41.52 \%$ \\
\hline \multirow[t]{2}{*}{ Q11 } & West & $35.30 \%$ & $45.07 \%$ & $19.63 \%$ & $48.70 \%$ & $21.10 \%$ & $30.21 \%$ \\
\hline & East & $17.78 \%$ & $38.59 \%$ & $43.64 \%$ & $28.18 \%$ & $15.35 \%$ & $56.46 \%$ \\
\hline \multirow[t]{2}{*}{ Q12 } & West & $32.86 \%$ & $41.59 \%$ & $25.54 \%$ & $42.41 \%$ & $20.93 \%$ & $36.66 \%$ \\
\hline & East & $19.60 \%$ & $41.62 \%$ & $38.79 \%$ & $26.57 \%$ & $21.82 \%$ & $51.62 \%$ \\
\hline \multirow[t]{2}{*}{ Q13 } & West & $30.80 \%$ & $51.74 \%$ & $17.46 \%$ & $50.98 \%$ & $19.96 \%$ & $29.07 \%$ \\
\hline & East & $30.91 \%$ & $44.55 \%$ & $24.55 \%$ & $48.89 \%$ & $18.79 \%$ & $32.32 \%$ \\
\hline \multirow[t]{2}{*}{ Q14 } & West & $24.13 \%$ & $48.64 \%$ & $27.22 \%$ & $38.39 \%$ & $21.58 \%$ & $40.02 \%$ \\
\hline & East & $19.60 \%$ & $48.99 \%$ & $31.41 \%$ & $33.84 \%$ & $22.02 \%$ & $44.14 \%$ \\
\hline \multirow[t]{2}{*}{ Q15 } & West & $28.09 \%$ & $50.65 \%$ & $21.26 \%$ & $42.84 \%$ & $25.05 \%$ & $32.10 \%$ \\
\hline & East & $23.03 \%$ & $42.12 \%$ & $34.85 \%$ & $35.15 \%$ & $21.52 \%$ & $43.33 \%$ \\
\hline \multirow[t]{2}{*}{ Q16 } & West & $26.74 \%$ & $32.70 \%$ & $40.56 \%$ & $34.60 \%$ & $12.04 \%$ & $53.36 \%$ \\
\hline & East & $22.02 \%$ & $30.71 \%$ & $47.27 \%$ & $29.19 \%$ & $12.53 \%$ & $58.28 \%$ \\
\hline \multirow[t]{2}{*}{ Q17 } & West & $14.26 \%$ & $37.58 \%$ & $48.16 \%$ & $21.53 \%$ & $15.46 \%$ & $63.02 \%$ \\
\hline & East & $17.68 \%$ & $37.27 \%$ & $45.05 \%$ & $26.26 \%$ & $15.25 \%$ & $58.48 \%$ \\
\hline \multirow[t]{2}{*}{ Q18 } & West & $70.17 \%$ & $24.19 \%$ & $5.64 \%$ & $79.18 \%$ & $10.74 \%$ & $10.09 \%$ \\
\hline & East & $80.81 \%$ & $15.05 \%$ & $4.14 \%$ & $86.67 \%$ & $7.07 \%$ & $6.26 \%$ \\
\hline \multirow[t]{2}{*}{ Q19 } & West & $4.72 \%$ & $17.30 \%$ & $77.98 \%$ & $7.54 \%$ & $6.13 \%$ & $86.33 \%$ \\
\hline & East & $4.65 \%$ & $10.71 \%$ & $84.65 \%$ & $7.17 \%$ & $3.33 \%$ & $89.49 \%$ \\
\hline \multirow[t]{2}{*}{ Q20 } & West & $7.75 \%$ & $25.87 \%$ & $66.38 \%$ & $10.85 \%$ & $10.57 \%$ & $78.58 \%$ \\
\hline & East & $6.46 \%$ & $24.85 \%$ & $68.69 \%$ & $9.39 \%$ & $10.40 \%$ & $80.20 \%$ \\
\hline Q21 & West & $28.47 \%$ & $26.84 \%$ & $44.69 \%$ & $37.80 \%$ & $11.06 \%$ & $51.14 \%$ \\
\hline & East & $20.61 \%$ & $25.05 \%$ & $54.34 \%$ & $26.36 \%$ & $13.03 \%$ & $60.61 \%$ \\
\hline
\end{tabular}


Table A3 continued: Distribution of Answers - West vs. East Germany

\begin{tabular}{|c|c|c|c|c|c|c|c|}
\hline \multicolumn{2}{|c|}{ "QUESTION \& REGION } & \multicolumn{3}{|c|}{ CODING $\mathrm{A}$} & \multicolumn{3}{|c|}{ CODING B } \\
\hline & & positive & medium & negative & positive & medium & negative \\
\hline \multirow{2}{*}{$\overline{Q 22}$} & West & $38.39 \%$ & $38.88 \%$ & $22.72 \%$ & $49.24 \%$ & $17.57 \%$ & $33.19 \%$ \\
\hline & East & $34.65 \%$ & $40.51 \%$ & $24.85 \%$ & $45.25 \%$ & $20.40 \%$ & $34.34 \%$ \\
\hline \multirow[t]{2}{*}{ Q23 } & West & $27.01 \%$ & $32.70 \%$ & $40.29 \%$ & $35.41 \%$ & $14.05 \%$ & $50.54 \%$ \\
\hline & East & $29.80 \%$ & $29.39 \%$ & $40.81 \%$ & $39.49 \%$ & $13.33 \%$ & $47.17 \%$ \\
\hline \multirow[t]{2}{*}{ Q24 } & West & $37.64 \%$ & $59.92 \%$ & $2.44 \%$ & $54.34 \%$ & $39.80 \%$ & $5.86 \%$ \\
\hline & East & $18.48 \%$ & $74.44 \%$ & $7.07 \%$ & $34.75 \%$ & $52.32 \%$ & $12.93 \%$ \\
\hline \multirow[t]{2}{*}{ Q25 } & West & $24.62 \%$ & $67.73 \%$ & $7.65 \%$ & $41.38 \%$ & $41.76 \%$ & $16.87 \%$ \\
\hline & East & $17.27 \%$ & $73.33 \%$ & $9.39 \%$ & $30.91 \%$ & $50.20 \%$ & $18.89 \%$ \\
\hline \multirow[t]{2}{*}{ Q26 } & West & $9.44 \%$ & $58.79 \%$ & $31.78 \%$ & $16.43 \%$ & $35.20 \%$ & $48.37 \%$ \\
\hline & East & $5.35 \%$ & $62.53 \%$ & $32.12 \%$ & $11.11 \%$ & $40.20 \%$ & $48.69 \%$ \\
\hline \multirow[t]{2}{*}{ Q27 } & West & $15.35 \%$ & $67.35 \%$ & $17.30 \%$ & $28.63 \%$ & $39.05 \%$ & $32.32 \%$ \\
\hline & East & $7.27 \%$ & $65.15 \%$ & $27.58 \%$ & $15.05 \%$ & $41.62 \%$ & $43.33 \%$ \\
\hline \multirow[t]{2}{*}{ Q28 } & West & $25.98 \%$ & $66.43 \%$ & $7.59 \%$ & $41.65 \%$ & $42.35 \%$ & $16.00 \%$ \\
\hline & East & $10.61 \%$ & $71.72 \%$ & $17.68 \%$ & $23.13 \%$ & $45.96 \%$ & $30.91 \%$ \\
\hline \multirow[t]{2}{*}{ Q29 } & West & $17.52 \%$ & $69.63 \%$ & $12.85 \%$ & $31.02 \%$ & $44.03 \%$ & $24.95 \%$ \\
\hline & East & $9.19 \%$ & $72.63 \%$ & $18.18 \%$ & $20.30 \%$ & $46.77 \%$ & $32.93 \%$ \\
\hline \multirow[t]{2}{*}{ Q30 } & West & $6.78 \%$ & $47.89 \%$ & $45.34 \%$ & $11.17 \%$ & $28.36 \%$ & $60.47 \%$ \\
\hline & East & $3.64 \%$ & $52.32 \%$ & $44.04 \%$ & $7.37 \%$ & $33.33 \%$ & $59.29 \%$ \\
\hline \multirow[t]{2}{*}{ Q31 } & West & $9.38 \%$ & $53.74 \%$ & $36.88 \%$ & $15.62 \%$ & $30.97 \%$ & $53.42 \%$ \\
\hline & East & $3.74 \%$ & $54.04 \%$ & $42.22 \%$ & $7.17 \%$ & $34.55 \%$ & $58.28 \%$ \\
\hline \multirow[t]{2}{*}{ Q32 } & West & $41.00 \%$ & $43.11 \%$ & $15.89 \%$ & $55.97 \%$ & $17.46 \%$ & $26.57 \%$ \\
\hline & East & $33.94 \%$ & $48.08 \%$ & $17.98 \%$ & $49.09 \%$ & $21.31 \%$ & $29.60 \%$ \\
\hline \multirow[t]{2}{*}{ Q33 } & West & $44.31 \%$ & $41.49 \%$ & $14.21 \%$ & $58.62 \%$ & $16.49 \%$ & $24.89 \%$ \\
\hline & East & $36.97 \%$ & $46.46 \%$ & $16.57 \%$ & $51.21 \%$ & $20.91 \%$ & $27.88 \%$ \\
\hline \multirow[t]{2}{*}{ Q34 } & West & $10.95 \%$ & $37.47 \%$ & $51.57 \%$ & $18.06 \%$ & $15.78 \%$ & $66.16 \%$ \\
\hline & East & $14.24 \%$ & $42.93 \%$ & $42.83 \%$ & $22.32 \%$ & $18.48 \%$ & $59.19 \%$ \\
\hline \multirow[t]{2}{*}{ Q35 } & West & $23.75 \%$ & $46.64 \%$ & $29.61 \%$ & $36.44 \%$ & $19.47 \%$ & $44.09 \%$ \\
\hline & East & $24.04 \%$ & $45.96 \%$ & $30.00 \%$ & $35.05 \%$ & $20.91 \%$ & $44.04 \%$ \\
\hline \multirow[t]{2}{*}{ Q36 } & West & $29.61 \%$ & $64.80 \%$ & $5.59 \%$ & $41.16 \%$ & $48.81 \%$ & $10.03 \%$ \\
\hline & East & $23.43 \%$ & $68.28 \%$ & $8.28 \%$ & $34.44 \%$ & $52.93 \%$ & $12.63 \%$ \\
\hline \multirow[t]{2}{*}{ Q37 } & West & $18.33 \%$ & $66.11 \%$ & $15.56 \%$ & $27.01 \%$ & $47.61 \%$ & $25.38 \%$ \\
\hline & East & $11.11 \%$ & $69.60 \%$ & $19.29 \%$ & $18.99 \%$ & $52.42 \%$ & $28.59 \%$ \\
\hline \multirow[t]{2}{*}{ Q38 } & West & $50.76 \%$ & $35.57 \%$ & $13.67 \%$ & $62.09 \%$ & $17.25 \%$ & $20.66 \%$ \\
\hline & East & $52.22 \%$ & $35.76 \%$ & $12.02 \%$ & $60.91 \%$ & $19.19 \%$ & $19.90 \%$ \\
\hline \multirow[t]{2}{*}{ Q39 } & West & $44.20 \%$ & $39.64 \%$ & $16.16 \%$ & $54.12 \%$ & $19.09 \%$ & $26.79 \%$ \\
\hline & East & $48.08 \%$ & $42.83 \%$ & $9.09 \%$ & $58.79 \%$ & $25.96 \%$ & $15.25 \%$ \\
\hline \multirow[t]{2}{*}{ Q40 } & West & $66.21 \%$ & $23.54 \%$ & $10.25 \%$ & $76.68 \%$ & $9.49 \%$ & $13.83 \%$ \\
\hline & East & $76.26 \%$ & $18.69 \%$ & $5.05 \%$ & $84.55 \%$ & $7.47 \%$ & $7.98 \%$ \\
\hline \multirow[t]{2}{*}{ Q41 } & West & $23.16 \%$ & $41.59 \%$ & $35.25 \%$ & $31.62 \%$ & $19.41 \%$ & $48.97 \%$ \\
\hline & East & $28.28 \%$ & $48.89 \%$ & $22.83 \%$ & $38.08 \%$ & $26.46 \%$ & $35.45 \%$ \\
\hline Q42 & West & $59.11 \%$ & $31.24 \%$ & $9.65 \%$ & $66.92 \%$ & $15.78 \%$ & $17.30 \%$ \\
\hline & East & $61.01 \%$ & $32.32 \%$ & $6.67 \%$ & $68.89 \%$ & $17.78 \%$ & $13.33 \%$ \\
\hline
\end{tabular}

For a description of the questions see Table A1 in the appendix. Total number of Observations: 2,834; 1,844 in West-Germany and 990 in East-Germany. 
Table A4: Description of Explanatory Variables

\begin{tabular}{l|l}
\hline \hline VARIABLE & DESCRIPTION \\
\hline East Germany & 1 if the respondent resides in East Germany; 0 otherwise \\
Female & 1 if the respondent is female; 0 otherwise \\
High Education & $\begin{array}{l}\text { 1 if the respondent holds a high schooling degree } \\
\text { (i.e. Hochschul- or Fachhochschulreife); 0 otherwise }\end{array}$ \\
Medium Education & $\begin{array}{l}\text { if the respondent holds a medium schooling degree } \\
\text { (i.e. Mittlere Reife); 0 otherwise }\end{array}$ \\
No formal Training & 1 if the respondent reports no formal training; 0 otherwise \\
Academic & 1 if the respondent reports an academic degree; 0 otherwise \\
Fears Loss of & 1 if the respondent reports to be afraid of loosing his or her job; \\
Employment & 0 otherwise \\
Not Employed & 1 if the respondent is not employed; 0 otherwise \\
Married & 1 if the respondent is married; 0 otherwise \\
Low Share of & 1 if the respondent resides in a region with less than $8 \%$ foreigner \\
Foreigners & share; 0 otherwise \\
Age & Age of respondent in years at time of the interview \\
\hline \hline
\end{tabular}




\section{IZA Discussion Papers}

\begin{tabular}{|c|c|c|c|c|}
\hline No. & Author(s) & Title & Area & Date \\
\hline 416 & $\begin{array}{l}\text { B. Crépon } \\
\text { F. Kramarz }\end{array}$ & $\begin{array}{l}\text { Employed } 40 \text { Hours or Not-Employed 39: } \\
\text { Lessons from the } 1982 \text { Mandatory Reduction of } \\
\text { the Workweek }\end{array}$ & 6 & $01 / 02$ \\
\hline 417 & J. Wagner & $\begin{array}{l}\text { Taking a Second Chance: } \\
\text { Entrepreneurial Restarters in Germany }\end{array}$ & 1 & $01 / 02$ \\
\hline 418 & $\begin{array}{l}\text { M. Frölich } \\
\text { P. A. Puhani }\end{array}$ & $\begin{array}{l}\text { Immigration and Heterogeneous Labor in } \\
\text { Western Germany: A Labor Market } \\
\text { Classification Based on Nonparametric } \\
\text { Estimation }\end{array}$ & 2 & $01 / 02$ \\
\hline 419 & $\begin{array}{l}\text { P. Frijters } \\
\text { J. P. Haisken-DeNew } \\
\text { M. A. Shields }\end{array}$ & $\begin{array}{l}\text { The Value of Reunification in Germany: } \\
\text { An Analysis of Changes in Life Satisfaction }\end{array}$ & 6 & $01 / 02$ \\
\hline 420 & $\begin{array}{l}\text { Å. Rosén } \\
\text { E. Wasmer }\end{array}$ & $\begin{array}{l}\text { Higher Education Levels, Firms' Outside Options } \\
\text { and the Wage Structure }\end{array}$ & 1 & $01 / 02$ \\
\hline 421 & P. Manzini & Divide et Impera: Negotiating with a Stakeholder & 6 & $02 / 02$ \\
\hline 422 & $\begin{array}{l}\text { J. T. Addison } \\
\text { L. Bellmann } \\
\text { C. Schnabel } \\
\text { J. Wagner }\end{array}$ & $\begin{array}{l}\text { The Long Awaited Reform of the German Works } \\
\text { Constitution Act }\end{array}$ & 6 & $02 / 02$ \\
\hline 423 & $\begin{array}{l}\text { E. Feess } \\
\text { G. Muehlheusser }\end{array}$ & Transfer Fee Regulations in European Football & 1 & $02 / 02$ \\
\hline 424 & $\begin{array}{l}\text { F. Büchel } \\
\text { M. van Ham }\end{array}$ & $\begin{array}{l}\text { Overeducation, Regional Labour Markets and } \\
\text { Spatial Flexibility }\end{array}$ & 3 & $02 / 02$ \\
\hline 425 & F. Büchel & $\begin{array}{l}\text { Successful Apprenticeship-to-Work Transitions: } \\
\text { On the Long-Term Change in Significance of the } \\
\text { German School-Leaving Certificate }\end{array}$ & 3 & $02 / 02$ \\
\hline 426 & $\begin{array}{l}\text { J. Hartog } \\
\text { W. P. M. Vijverberg }\end{array}$ & $\begin{array}{l}\text { Do Wages Really Compensate for Risk Aversion } \\
\text { and Skewness Affection? }\end{array}$ & 5 & $02 / 02$ \\
\hline 427 & D. Del Boca & $\begin{array}{l}\text { The Effect of Child Care and Part Time } \\
\text { Opportunities on Participation and Fertility } \\
\text { Decisions in Italy }\end{array}$ & 6 & $02 / 02$ \\
\hline 428 & D. Del Boca & $\begin{array}{l}\text { Mothers, Fathers and Children after Divorce: } \\
\text { The Role of Institutions }\end{array}$ & 6 & $02 / 02$ \\
\hline 429 & $\begin{array}{l}\text { S. Anger } \\
\text { J. Schwarze }\end{array}$ & $\begin{array}{l}\text { Does Future PC Use Determine Our Wages } \\
\text { Today? Evidence from German Panel Data }\end{array}$ & 5 & $02 / 02$ \\
\hline 430 & $\begin{array}{l}\text { J. Schwarze } \\
\text { M. Härpfer }\end{array}$ & $\begin{array}{l}\text { Are People Inequality Averse, and Do They } \\
\text { Prefer Redistribution by the State? Evidence } \\
\text { From German Longitudinal Data on Life } \\
\text { Satisfaction }\end{array}$ & 3 & $02 / 02$ \\
\hline 431 & $\begin{array}{l}\text { M. Fertig } \\
\text { C. M. Schmidt }\end{array}$ & $\begin{array}{l}\text { The Perception of Foreigners and Jews in } \\
\text { Germany - A Structural Analysis of a Large } \\
\text { Opinion Survey }\end{array}$ & 6 & $02 / 02$ \\
\hline
\end{tabular}

An updated list of IZA Discussion Papers is available on the center's homepage www.iza.org. 